\title{
The transcription factor Net regulates the angiogenic switch
}

\author{
Hong Zheng, ${ }^{1}$ Christine Wasylyk, ${ }^{1}$ Abdelkader Ayadi, ${ }^{1}$ Joseph Abecassis, ${ }^{2}$ Jack A Schalken, ${ }^{3}$ \\ Hermann Rogatsch, ${ }^{4}$ Nicolas Wernert, ${ }^{5}$ Sauveur-Michel Maira, ${ }^{1,7}$ Marie-Christine Multon, ${ }^{6}$ and \\ Bohdan Wasylyk ${ }^{1,8}$ \\ ${ }^{1}$ Institut de Génétique et de Biologie Moléculaire et Cellulaire, CNRS/INSERM/ULP, 67404 Illkirch Cedex, France; ${ }^{2}$ UPRES \\ EA 34-30, Centre Paul Strauss, 67085 Strasbourg Cedex, France; ${ }^{3}$ University Hospital Nijmegen, 6500 HB Nijmegen, \\ The Netherlands; ${ }^{4}$ Department of Urology, University of Innsbruck, A-6020 Innsbruck, Austria; ${ }^{5}$ Institute of Pathology, \\ University of Bonn, 53011 Bonn, Germany; ${ }^{6}$ Aventis, Recherche-Développement, 94403 Vitry-sur-seine, France
}

\begin{abstract}
Angiogenesis is fundamental to physiological and pathological processes. Despite intensive efforts, little is known about the intracellular circuits that regulate angiogenesis. The transcription factor Net is activated by phosphorylation induced by Ras, an indirect regulator of angiogenesis. Net is expressed at sites of vasculogenesis and angiogenesis during early mouse development, suggesting that it could have a role in blood vessel formation. We show here that down-regulation of Net inhibits angiogenesis and vascular endothelial growth factor (VEGF) expression in vivo, ex vivo, and in vitro. Ras-activated phosphorylated Net (P-Net) stimulates the mouse VEGF promoter through the -80 to -53 region that principally binds Sp1. P-Net and VEGF are coexpressed in angiogenic processes in wild-type mouse tissues and in human tumors. We conclude that Net is a regulator of angiogenesis that can switch to an activator following induction by pro-angiogenic molecules.
\end{abstract}

[Keywords: Wound healing; tumors; VEGF; Sp1; KSHV-GPCR]

Received May 13, 2003; revised version accepted July 11, 2003.

The process of forming new blood vessels, angiogenesis, occurs throughout embryonic development and in all fetal organs. In adult mammals, angiogenesis is restricted to pathological situations including tumors and wound healing, and some natural processes such as the female reproductive cycle. Counterbalancing positive and negative factors regulate angiogenesis. During angiogenesis, growth factors, generated by surrounding normal or tumor cells, induce quiescent endothelial cells to proliferate and differentiate, to form new blood vessels that facilitate material exchange. An important unresolved question is which intracellular circuits regulate this "angiogenic switch" (Carmeliet and Jain 2000). One of the most potent positive factors is vascular endothelial growth factor (VEGF), an endothelial cell-specific mitogen that plays a central role in neovascularization (Ferrara and Davis-Smyth 1997). The molecular mechanisms of the regulation of VEGF expression during this "switch" are still incompletely understood, but are known to involve hypoxia, growth factors, and transformation. Hypoxia induces VEGF expression through in-

${ }^{7}$ Present address: Novartis Pharma AG, BU Oncology, In Vivo Pharmacology, Klybeckstrasse, CH4002 Basel, Switzerland.

${ }^{8}$ Corresponding author.

E-MAIL boh@titus.u-strasbg.fr; FAX 33-3-8865-3201.

Article published online ahead of print. Article and publication date are at http://www.genesdev.org/cgi/doi/10.1101/gad.272503. creased transcription mediated by hypoxia-inducible factor 1 (HIF-1; Forsythe et al. 1996). A variety of growth factors and serum up-regulate VEGF in quiescent human keratinocytes, a process thought to be important in wound healing (Frank et al. 1995). The Kaposi's sarcomaassociated herpesvirus (KSHV/HHV8) stimulates angiogenesis. The G-protein-coupled receptor (KSHV-GPCR) encoded by open reading frame (ORF) 74 induces cell transformation, tumorigenicity, and a switch to an angiogenic phenotype mediated by VEGF (Bais et al. 1998). Overexpression of the oncogenes Ras, v-Raf, and v-Src (Grugel et al. 1995; Mukhopadhyay et al. 1995; Rak et al. 1995) leads to increased expression of VEGF, which is thought to be important for tumor angiogenesis.

Growth factors and oncogenes such as Ras induce MAP kinase signaling cascades that transduce extracellular signals from ligand-activated cell surface receptors to the nucleus. MAP kinases phosphorylate nuclear effectors, such as members of the ets family of transcription factors (Sharrocks 2001). In particular, MAP kinase phosphorylation enhances the ability of the three ternary complex factor (TCF) Ets factors (Net, Elk-1, and Sap-1) to activate transcription of many immediate early response genes (Treisman 1994). Despite considerable interest in the role of the TCFs in signaling, their physiological roles remain unclear.

Net (Elk-3/Sap-2/ERP) is a repressor of transcription 
that is converted to a positive regulator by Ras and Src signaling. Net is activated through phosphorylation of critical residues of the C-terminal $(\mathrm{C})$ domain (Giovane et al. 1994; Maira et al. 1996; Criqui-Filipe et al. 1999). We have found that at early stages of mouse development, net RNA is expressed at sites of vasculogenesis and angiogenesis, raising the possibility that Net is involved in angiogenesis. Later, around birth and in the adult, net is widely expressed in different tissues and cell types (Ayadi et al. 2001a; data not shown). Homozygous net mutant mice, which express a Net mutant protein that lacks the Ets DNA-binding domain (Net $\delta$ ), develop a vascular defect. A large proportion of the mice die just after birth due to respiratory failure, resulting from the accumulation of chyle in the thoracic cage (chylothorax). The mice have dilated lymphatic vessels (lymphangiectasis) as early as embryonic day 16.5 (E16.5). They express more egr-1 in heart and pulmonary arteries at E18.5, suggesting that Net is a negative regulator of egr-1 in vivo. However, we did not observe any obvious malformations of blood vessels in mutant embryos or adults (Ayadi et al. 2001b). These results suggest that Net is implicated in vascular biology and raise the possibility that Net may have a positive role in angiogenesis in the adult. Consequently, we studied the contribution of Net to angiogenesis in wound healing, in several in vitro, ex vivo, and in vivo assays, in experimental tumors, and in different types of human tumors. Our results provide strong evidence that phosphorylated Net (P-Net) is a positive regulator of angiogenesis, at least in part through effects on VEGF expression.

\section{Results}

Net is required for angiogenesis and VEGF expression during skin wound healing

Angiogenesis plays a fundamental role in skin wound healing. Dense capillary plexuses as well as inflammatory cells and fibroblasts form the granulation tissue that replaces the temporary fibrin clot. The granulation tissue produces the VEGF that plays an important role in this process. At earlier stages, invading keratinocytes at the wound edge also produce VEGF (Martin 1997; Kishimoto et al. 2000). We compared the rate of wound healing in $n e t^{\delta / \delta}$ and wild-type littermate adult mice. This experiment is possible because about $10 \%$ of net $t^{\delta / \delta}$ mice survive beyond 4 wk of age (Ayadi et al. 2001b). We generated full-thickness wounds on the dorsal skin, and then photographed and measured the size of the wounds at regular intervals. The wounds in net ${ }^{\delta / \delta}$ mice heal significantly more slowly than in the wild type (Fig. 1A,B). We studied blood vessel formation $6 \mathrm{~d}$ after wounding, an intermediate time at which the wounds were healing at a high rate, hyperplastic epidermis had migrated to cover the denuded wound surface, and the provisional fibrin matrix was partially replaced by granulation tissue. Blood vessels were detected by immunohistochemistry (IHC) with antibodies against CD31 (Fig. 1C). Vessel density was considerably reduced in the $n e t^{\mathrm{s} / \delta}$ mice at the edges and in the bed of the wounds. The proportion of the area occupied by vessels in different optical fields was examined in five pairs of wild-type and mutant mice. The proportion was $38 \% \pm 3 \%$ in the wild type compared to $18 \% \pm 4 \%$ in the $n e t^{\delta / \delta}$ mice $(P<0.01)$. The number of vessels per $\mathrm{mm}^{2}$ was $396 \pm 33$ in the wild type versus $182 \pm 50$ in $n e t^{\delta / \delta}$ mice $(P<0.005$; see Materials and Methods). These results show that there is decreased angiogenesis in the $n e t^{\delta / \delta}$ mice. We examined adjacent sections for VEGF expression. As expected, in the wild-type mice, VEGF was highly expressed by mononuclear cells (probably macrophages and wound fibroblasts) in the granulation tissue in the bed and at the edge of the wounds (Fig. 1D, arrows). In contrast, VEGF expression was much lower in $n e t^{\delta / \delta}$ mice, with only a few cells expressing levels similar to the wild type (indicated by arrows in Fig. 1D). These results suggest that the decreased angiogenesis in $n e t^{\delta / \delta}$ mice could be due to decreased expression of VEGF.

If Net positively regulates angiogenesis through effects on VEGF expression, then VEGF-expressing cells should also contain activated Net, phosphorylated on critical residues of the $\mathrm{C}$-terminal activation domain. We previously described phospho-Net-specific antibodies targeted around critical amino acids, phospho-Ser 365 (2F3) or phospho-Thr 329 (1F12). These antibodies have been characterized by ELISA with phosphorylated and nonphosphorylated peptides, Western blotting and IHC, and shown not to interact with nonphosphorylated Net, or phosphorylated Elk that is detected by phospho-Elk-specific antibodies (Ducret et al. 2000; data not shown). Cryosections of 6-day-old wounds were dual-stained with P-Net and VEGF antibodies (Fig. 1E). VEGF and P-Net were found to be up-regulated in the same cells, in the newly formed keratinocytes and granular mononuclear cells. Groups of cells closer to the wound stain more strongly for both P-Net and VEGF than those further away. VEGF was detected in the cytoplasm and PNet in the nucleus of the same cells, and cells stained strongly or weakly for both. The two P-Net antibodies gave similar results (data not shown). The secondary antibodies alone did not give any staining (data not shown). These results show that P-Net is expressed in the cells that produce VEGF, $6 \mathrm{~d}$ after wounding.

Earlier during wound healing (after $48 \mathrm{~h}$ ), VEGF is expressed by the activated keratinocytes close to the wound, and expression decreases with distance from the wound (Fig. 1F, cf. arrows and arrowhead; Kishimoto et al. 2000). In adjacent sections, P-Net was found to be expressed in the activated keratinocytes close to the wound (Fig. 1G, arrows), and the levels of expression decrease to low levels in the epidermis far from the wound (Fig. 1G, arrowhead). These results show that PNet is expressed in the same types of cells and in the same pattern as VEGF. Overall, these results show that during wound healing Net is phosphorylated on amino acids that are critical for activation of its transcription function. P-Net is detected in mononuclear cells in the granulation tissue and in activated keratinocytes. Wound healing, angiogenesis, and VEGF expression are 
A

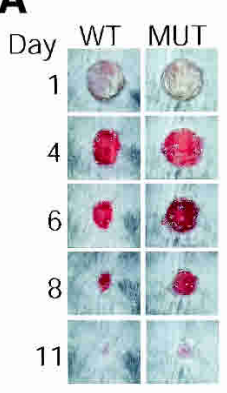

B

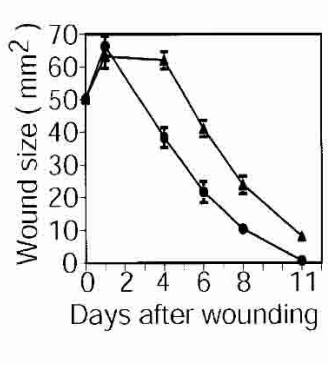

C WIIDYPE CD31

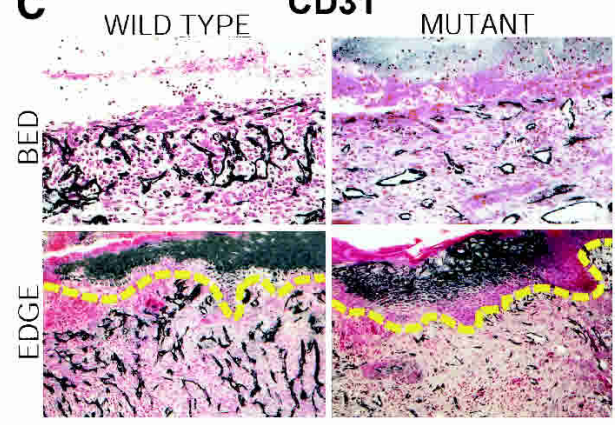

D

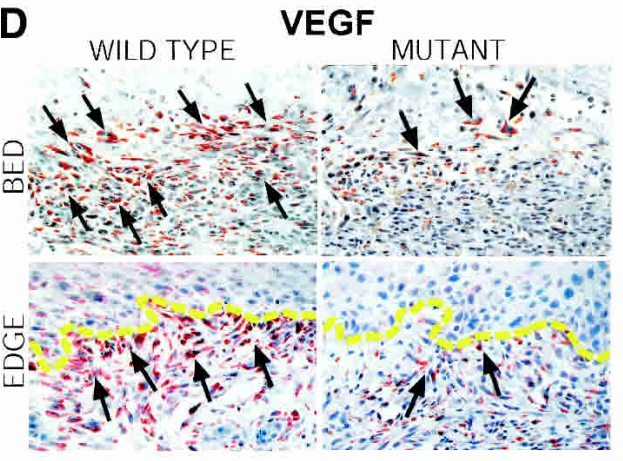

E
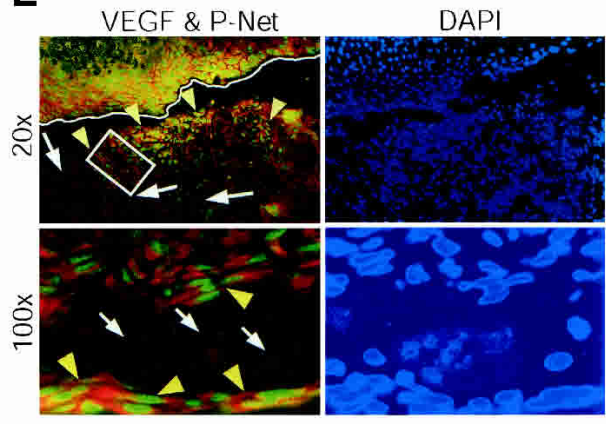

$\mathbf{F}$

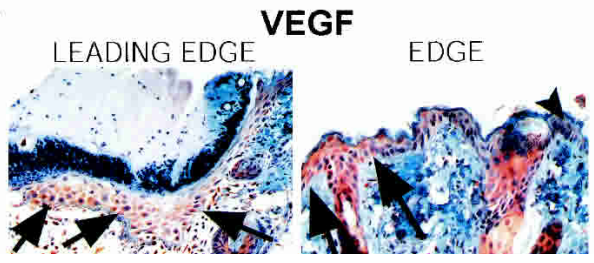

G

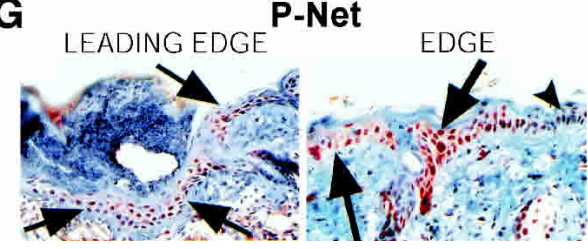

Figure 1. Impaired angiogenesis during wound healing in $n e t^{\delta / \delta}$ mice. $(A)$ Macroscopic view of skin wound healing in $n e t^{\delta / \delta}(M U T)$ mice and wild-type (WT) littermates. $(B)$ Time course of skin wound healing. ( $)$ Wild type; $(\mathbf{\Lambda})$ mutant. Twelve pairs of mice were tested. $P<0.005 .(C)$ CD31 staining of blood vessels. There are fewer vessels (black stain) in the bed and edge of net $t^{\delta / \delta}(M U T A N T)$ compared to wild type. The broken yellow lines delimit the dermis. Magnification: bed, 40x; edge, 20x. (D) VEGF staining $6 \mathrm{~d}$ after wounding. Fewer cells express VEGF (brown stain, see arrows) in $n e t^{\delta / \delta}$ compared to wild-type mice. The broken yellow lines delimit the dermis. Magnification, 63×. (E) Colocalization of VEGF and P-Net expression. Cryosections of the wound $6 \mathrm{~d}$ after wounding were stained for VEGF (red), P-Net (green), and nuclei (blue, DAPI). The white line separates the activated keratinocytes (above) from the granulation tissue mononuclear cells (below). Yellow arrowheads indicate cells intensely staining for both VEGF and P-Net, white arrows indicate cells poorly staining for both. The white rectangle in the 20x magnification indicates the region shown in the 100x magnification. $(F, G)$ P-Net $(F)$ and VEGF $(G)$ staining (brown) of skin $48 \mathrm{~h}$ after wounding. Activated keratinocytes (arrows) close to the wound and quiescent keratinocytes (arrowheads) far from the wound are indicated. Magnification, 63×.

impaired in net mutant mice, suggesting that Net is a positive regulator of angiogenesis and VEGF expression during wound healing in adult mice.

\section{Net is required for angiogenesis induced by transformed cells in mice}

To study the role of Net in angiogenesis in solid tumors, we established stable clones of NIH3T3 cells expressing KSHV-GPCR, a viral oncogene and a potent angiogenesis activator (Bais et al. 1998). Clones with reduced levels of Net were prepared by cotransfecting a vector that expresses antisense-net (net sequences in the reserve orientation in the expression vector). This method was shown to specifically down-regulate net expression (Gio- vane et al. 1994). We further confirmed that the antisense is specific by Western blotting. In the transformed clones, antisense-net decreased the levels of endogenous Net without affecting the highly related Elk-1 (75\% at the protein level; Fig. 2A; data not shown). Furthermore, in short-term transfections, antisense-net decreased endogenous Net without affecting Elk-1, Ras, or KSHVGPCR expression (data not shown), demonstrating that antisense-net specifically down-regulates Net. The antisense-net clones grew normally according to cell-cycle analysis by FACS (data not shown).

The KSHV-GPCR clones were injected subcutaneously in nude mice. The clones with normal levels of Net formed rapidly growing tumors, reaching a volume of $200-300 \mathrm{~mm}^{3}$ in $16 \mathrm{~d}$ (Fig. 2B). The tumors were red 
Zheng et al.

A

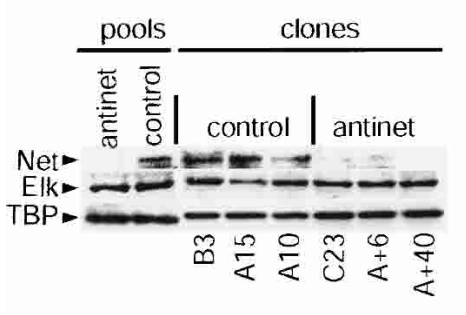

D

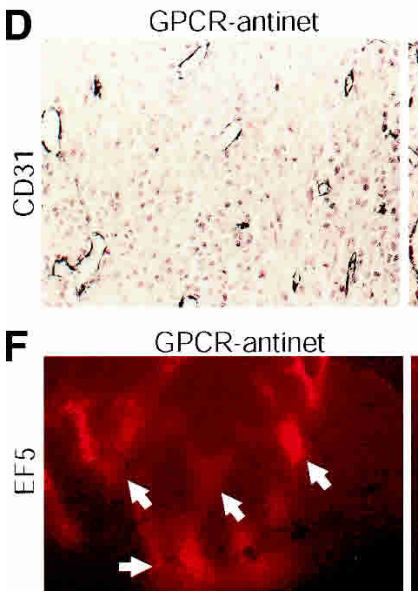

B

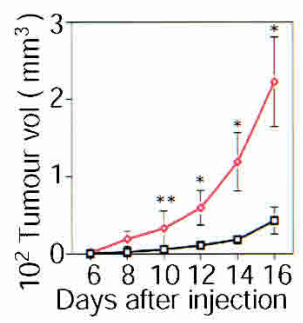

GPCR-control

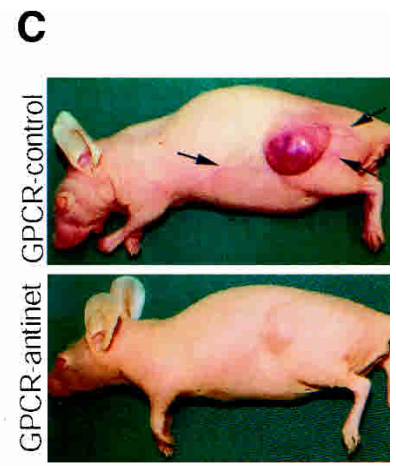

E

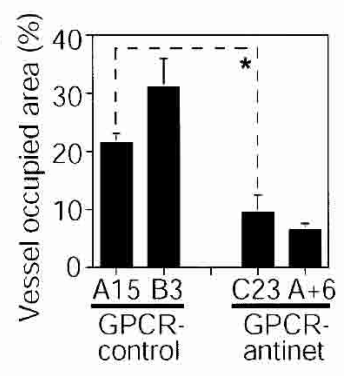

Figure 2. Impaired tumor induced angiogenesis in Net-deficient tumors. (A) Western blot analysis of endogenous Net, Elk-1, and TBP in GPCR-transformed clones. GPCR-anti-net clones: C23, A + 6, A + 40. GPCR-control vector (pEGFP-N1) clones: B3, A15, A10. (B) Volumes of GPCR-anti-net (black line) and GPCR-control (red line) clone tumors in nude mice (24 GPCR-control tumors vs. 16 GPCR-anti-net tumors). $\left(^{\star}\right) P<0.01 ;\left(^{\star \star}\right) P<0.05$. $(C)$ GPCR-control and GPCR-anti-net tumors in nude mice. GPCR-control tumors have a red hemorrhagic phenotype and attract supplying blood vessels (arrows), whereas GPCR-anti-net tumors are white and attract few vessels. (D) Vessels in GPCR and GPCR-anti-net tumors detected with anti-CD31 (dark-gray reaction; safranine staining for morphology) Magnification, 40x. Sections were prepared from 16-d tumors and processed for IHC. (E) Quantitative analysis of vessels. The "vessel-occupied area" is the proportion of the total area that is occupied by vessels with their walls and lumens. Vessels were evaluated in four randomly selected $40 \times$ fields in sections from three different tumors for each clone. $\left({ }^{\star}\right) P<0.01$, control versus anti-net clones. $(F)$ Tumor hypoxic tension measured by the EF5 technique. The red fluorescent areas indicated by arrows are the hypoxic regions of the tumor sections. Magnification, $5 \times$.

and hemorrhagic, and induced newly formed supplying blood vessels (Fig. 2C, arrows). In contrast, the clones with decreased levels of Net grew more slowly, and the tumors were white and poorly vascularized. Vessels in the tumors were examined by IHC for the CD31 marker (Fig. 2D, dark-gray stain). There was a significant rarefaction of vessels in the KSHV-GPCR-antisense-net tumors compared to the KSHV-GPCR controls. The proportion of the area occupied by vessels (vessel-occupied area, Fig. $2 \mathrm{E}$ ) was reduced by about $75 \%$. Moreover, the vessels in the GPCR-anti-net tumors were relatively smaller. There was a marked decrease in vessels larger than 2000 $\mu^{2}$ in the GPCR-anti-net tumors (number of vessels larger than $2000 \mathrm{\mu m}^{2}$, GPCR-anti-net tumors/GPCRcontrol tumors, $32 \pm 3 \%, n=5, P<0.01)$, but not in vessels smaller than $2000 \mu \mathrm{m} 2$ (number of vessels smaller

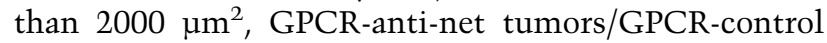
tumors, $113 \pm 26 \%, n=5, P<0.01)$. Similar data were obtained with six KSHV-GPCR-control clones (24 tumors) and four KSHV-GPCR-antisense-net clones (16 tumors). The difference in vascularity between the two types of tumors was maintained, even when equivalent- sized tumors were evaluated (data not shown). The reduced vessel density would be expected to reduce the oxygen tension. In the tumors, the oxygen tension was measured by EF5 immunodetection (Fig. 2F); KSHVGPCR tumors that lack Net had a lower oxygen tension (see overall stronger red staining, in particular the regions indicated by arrows), as expected from the reduced blood vessel density. These results show that Net is required for angiogenesis induced by transformed cells in vivo.

Net is required for angiogenesis in ex vivo and in vitro model systems

Three different assays were used to study the role of Net in angiogenesis: corneal micropockets (Kenyon et al. 1996), aortic rings (Nicosia and Ottinetti 1990; Nicosia et al. 1997), and microtubule formation by HUVEC cells in Matrigel (Bais et al. 1998). For the corneal micropocket assay, FGF-2 pellets were implanted in the cornea of wild-type and $n e t^{\delta / \delta}$ littermates. FGF-2 clearly induced vessel formation in the wild-type cornea (Fig. 3A; 
A
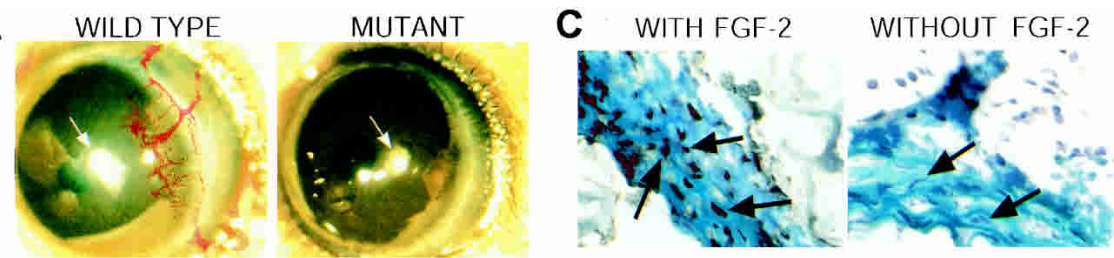

B

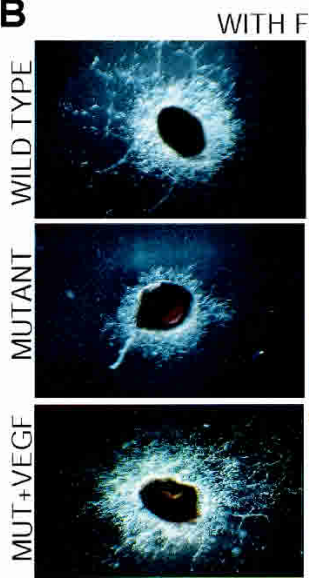

WITH FGF-2

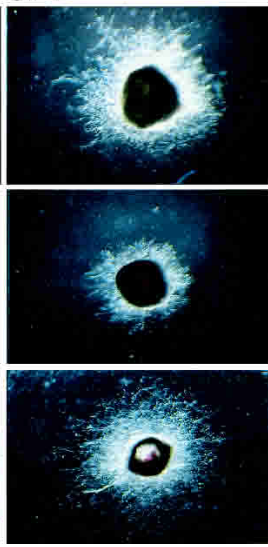

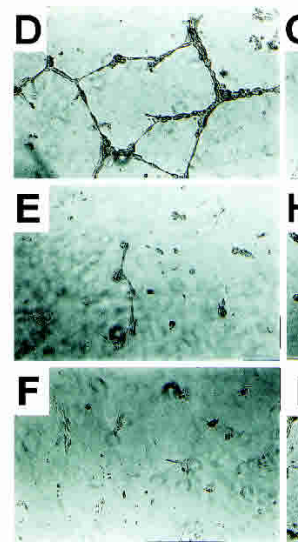

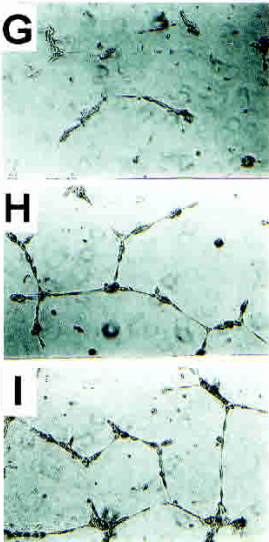

Figure 3. Net is required for angiogenesis in model systems. (A) Corneal pocket assay. FGF-2 induces angiogenesis in the cornea of wild-type but not $n e t^{\delta / \delta}$ mice. Circles are FGF-2 beads. $(B)$ Microvessel sprouting from aortic rings. Pairs of aortic rings from net $t^{\delta / \delta}$ (MUTANT) and wild-type mice are shown. The Matrigel-embedded rings were covered by EBM medium with FGF-2 $(40 \mathrm{ng} / \mathrm{mL})$ and VEGF $(60 \mathrm{ng} / \mathrm{mL})$ where indicated. $(C)$ P-Net expression in aortic rings. Aortic rings were cultured in Matrigel with or without FGF-2 (40 $\mathrm{ng} / \mathrm{mL}$ ). Four days later the rings with the sprouts were collected for frozen sections and processed for IHC. P-Net is expressed in smooth muscle cells of aortic rings only after FGF-2 treatment (arrowheads). Magnification, 100×. $(D-I)$ HUVEC microtube formation induced by conditioned medium from transfected NIH3T3 cells. The transfections contained the GPCR vector and the empty vector for antisense net $(\mathrm{p} 601 \mathrm{D} ; D)$, the GPCR and antisense net vectors $(E)$, and the GPCR and TD-

Net (trans-dominant Net) vectors $(F)$. The conditioned media used in $G-I$ were the same as for $D-F$ respectively, but with additions. $G$ shows $D$ preincubated with $0.2 \mu \mathrm{g} / \mathrm{mL}$ anti-VEGF antibody, $H$ shows $E$ with $10 \mathrm{ng} / \mathrm{mL}$ VEGF peptide, and $I$ shows $F$ with $10 \mathrm{ng} / \mathrm{mL}$ VEGF peptide.

note that on the mixed BL/6x129 background used for these experiments, fewer vessels are induced than on some other backgrounds; see Rohan et al. 2000). The FGF-2-induced vascular response was strongly impaired in the cornea of $n e t^{\delta / \delta}$ mutant mice (Fig. 3A). Similar results were obtained in eight pairs of cornea from four pairs of $n e t^{\delta / \delta}$ and wild-type littermates.

In the aortic ring assay, FGF-2-induced sprouting from $n e t^{\delta / \delta}$ aortic rings was severely impaired compared to wild type after $4 \mathrm{~d}$ in culture (Fig. 3B; six rings from each animal from four $n e t^{\delta / \delta}$ and four wild-type littermates were analyzed, with similar results). VEGF addition restored sprouting from the $n e t^{\delta / \delta}$ aortic rings to levels similar to the wild type, suggesting that impaired production of VEGF is responsible for the decreased sprouting. IHC analysis of sections of the aortas with P-Netspecific antibodies showed that FGF-2 induced phosphorylation of Net in smooth muscle cells in the aortic wall but not in the sprouting cells (Fig. 3C). The ERK cascade-specific inhibitor U0126 (10 $\mu \mathrm{M})$ inhibited sprouting in the presence of FGF-2, and washing out the inhibitor restored sprouting (data not shown). These results indicate that FGF-2-induced phosphorylation of Net through the MAP kinase pathway converts Net to an activator of angiogenic processes.

Conditioned medium from KSHV-GPCR-expressing NIH3T3 cells has been reported to contain pro-angiogenic factors that induce microtubule formation by HUVEC cells in Matrigel (Fig. 3D; Bais et al. 1998). We tested whether down-regulation of Net affected KSHVGPCR-induced secretion of "microtube-forming" activity. Conditioned medium from fibroblasts transfected with KSHV-GPCR and antisense net vectors had reduced microtube-forming activity (Fig. 3, cf. D and E). Similar reduced microtube-forming activity was observed by the expression of a transdominant Net mutant (Fig. 3F, TD-Net, Net 219-409) that has been shown to inhibit transactivation by Net (Maira et al. 1996; data not shown). These results show that down-regulation of Net inhibits the secretion of HUVEC "microtube-forming" activity. VEGF has been shown to be a critical component of this activity, as microtube formation is inhibited by antibodies against VEGF (Fig. 3G; Bais et al. 1998). VEGF is also apparently the critical component affected by down-regulating Net, because adding VEGF to the conditioned media restored microtubule formation (Fig. 3, cf. E and H, F and I). These results suggest that down-regulation of Net inhibits VEGF expression (see below). In conclusion, Net is required for angiogenesis in three different models of angiogenesis.

\section{Regulation of VEGF expression by Net}

Oncogenic H-Ras (Ras-V12) and KSHV-GPCR induce angiogenesis by increasing VEGF secretion (Arbiser et al. 1997; Bais et al. 1998; Boshoff and Weiss 1998). We investigated the mechanisms by which Net may be involved in these pathways. We showed previously that Ras-V12 induces Net phosphorylation by an ERK1/2-dependent pathway (Fig. 4A; Ducret et al. 2000). We found that KSHV-GPCR expression in NIH3T3 fibroblasts also stimulates endogenous Net phosphorylation through ERK- and p38 pathway-dependent mechanisms, as shown using the pathway-specific inhibitors U0126 and 
Zheng et al.
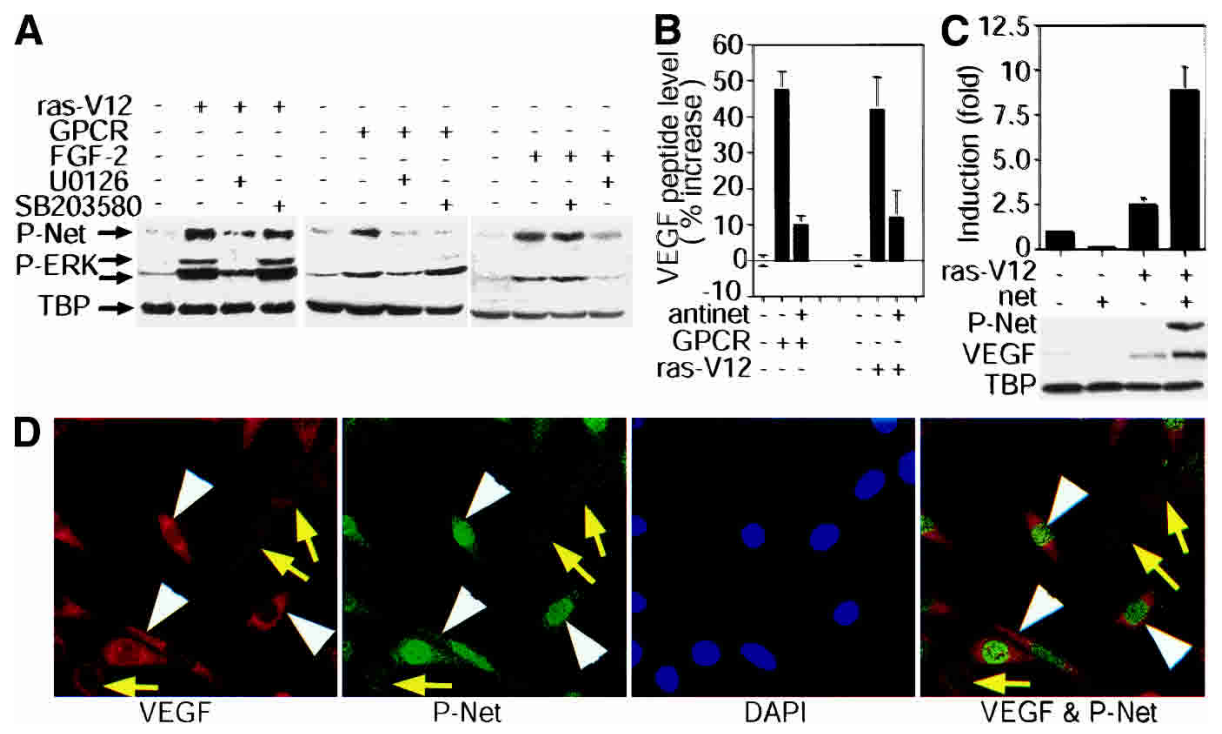

Figure 4. Net regulation of VEGF expression in cell culture. $(A)$ Endogenous Net is phosphorylated by GPCR, Ras, and FGF-2 through MAP kinase cascades. NIH3T3 cells were transfected with expression vectors for KSHV-GPCR or Ras-V12, or induced with FGF-2. Cell extracts were analyzed by Western blotting for P-Net, activated P-ERK, and TBP (control for loading). (B) Down-regulation of Net inhibits VEGF expression induced by GPCR and Ras-V12. NIH3T3 cells were transfected with GPCR, Ras-V12, antisense net, and corresponding control vectors, as indicated. Transfected cells were kept in $0.5 \%$ FCS medium for $48 \mathrm{~h}$ after the wash. VEGF in this conditioned media was measured by ELISA. Results are averaged from four independent transfection experiments (corrected for cell numbers). (C) P-Net regulates VEGF promoter activity and stimulates endogenous VEGF expression. NIH3T3 cells were transfected with the mouse VEGF promoter luciferase reporter $(-1217 /+370)$, the pCMV LacZ internal control, and expression vectors for Net and Ras-V12. VEGF promoter activity relative to the transfections with empty vectors was determined (graph). Cell extracts were analyzed by Western blotting for the expression of P-Net, endogenous VEGF, and TBP (loading control; lower panels). (D) Coexpression of P-Net and VEGF in transfected cells. NIH3T3 cells were transfected with expression vectors for P-Net and Ras-V12. The cells were stained with antibodies against VEGF and P-Net, corresponding fluorescent secondary antibodies, and DAPI (nuclei), and examined by confocal microscopy. Transfected cells fluoresced brightly (white arrowheads), with VEGF (red) in the cytoplasm and P-Net (green) in the nucleus. Nontransfected cells gave clearly lower fluorescence signals (yellow arrows).

SB203580, respectively (Fig. 4A). This agrees with previous studies showing that KSHV-GPCR stimulates both pathways (Bais et al. 1998). In addition, we showed that KSHV-GPCR stimulated Net transcriptional activity in transfection assays (data not shown). Because downregulation of Net inhibits FGF-2-induced angiogenesis in several assays (see above), we also investigated FGF-2. We found that FGF-2 induces Net phosphorylation through an ERK-1/2-dependent pathway (Fig. 4A).

We studied whether down-regulation of Net inhibits VEGF expression, by measuring VEGF peptide levels in condition media with an ELISA assay. As expected, VEGF levels were increased by the expression of KSHVGPCR or oncogenic Ras-V12 (Fig. 4B). VEGF induction was inhibited by down-regulation of Net with antisense. These results show that Net is required for VEGF expression. To investigate whether Net regulates VEGF promoter activity, we used transfection assays with a mouse VEGF promoter-luciferase reporter, and we either downregulated Net with antisense or increased Net levels with expression vectors. A control reporter (pCMVLacZ) was systematically cotransfected as an internal control. We found that the VEGF promoter is activated by the expression of KSHV-GPCR, and that decreasing the level of endogenous Net with antisense inhibits this activation, without affecting control promoters $(\mathrm{mdm} 2$ - luc and $21^{\mathrm{WAF} 1}-$ luc; data not shown). Increasing activated P-Net levels, by the expression of exogenous Net together with Ras-V12, stimulated VEGF promoter activity $(-1217 /+370 \mathrm{Luc})$ to a fourfold higher level than Ras-V12 alone (Fig. 4C). Expression of Net without RasV12 did not stimulate the VEGF promoter. Western blots were used to show that P-Net levels increased in the presence of Ras-V12. Furthermore, endogenous VEGF expression, at the protein and RNA levels, was increased by Net + Ras-V12 expression compared to Ras-V12 or Net alone, or in the absence of exogenous proteins (Fig. $4 \mathrm{C}$; data not shown).

To show that endogenous VEGF expression is increased in the same cells that have elevated levels of P-Net, we used immunocytochemistry (ICC) with antibodies against VEGF and P-Net on cells transfected with Net and Ras-V12 expression vectors. About $15 \%$ of the cells were transfected and contained elevated levels of P-Net in the nucleus (Fig. 4D, cf. the bright-green nuclei indicated by white arrowheads and the darker nuclei indicated by yellow arrows; see also the DAPI-stained blue nuclei). A similar proportion of cells contained elevated levels of VEGF in the cytoplasm (Fig. 4D, bright-red cells indicated by white arrowheads). Combining both signals (Fig. 4D, VEGF and P-Net) showed that the majority $(75 \% \pm 5 \%)$ of cells that contained high levels of one of 
the signals also contained the other (Fig. 4D, white arrowheads; about 400 cells in different fields were counted in four independent experiments). Transfections with empty vectors or the Net vector alone gave only background staining (similar to the nontransfected cells when both vectors were included; data not shown). Transfections with the Ras-V12 vector gave a small increase in VEGF- and P-Net-positive cells, but the number of positive cells was over fivefold lower than that obtained with both vectors (data not shown). This could be due to Ras-V12 phosphorylation of endogenous Net and increased expression of VEGF. Taken together, these results show that P-Net positively regulates VEGF expression and VEGF promoter activity.

The region of the mouse VEGF promoter that contains two Sp1 motifs mediates Net + Ras-V12 activation

The mouse VEGF promoter contains different motifs (Shima et al. 1996), including a hypoxia responsive ele- ment (HRF; Oosthuyse et al. 2001) and two proximal Sp1 motifs (Maeno et al. 2002). There are a number of other putative motifs; some of those in the $-449 /+1$ region are shown in Figure 5A. We localized the elements that mediate VEGF promoter activation by Net + Ras-V12 with a series of upstream and downstream deletion mutants. Deletion mutants lacking sequences up to $-449,-204$, -125 , and -80 were efficiently activated by cotransfection of the Net and Ras-V12 expression vectors, compared to cotransfections with either of the vectors alone, or the empty vectors (whose value is set to 1). The levels of activation were similar to the $-1217 /+370$ reporter (Fig. 4C), indicating that sequences upstream from -80 are not required for Net + Ras-V12 activation. Further mutation of the upstream Sp1 motif (GGGGCGGG to CTCGAGGG) decreased Net + Ras-V12 activation, and deletion of both motifs $(-53$ to -40$)$ reduced activation to an even greater extent. Point mutation of the two ets sites at -37 to -18 in various contexts $(-40,-80,-125$, or -204 to +370 ) had no effect on Net + Ras-V12 activation

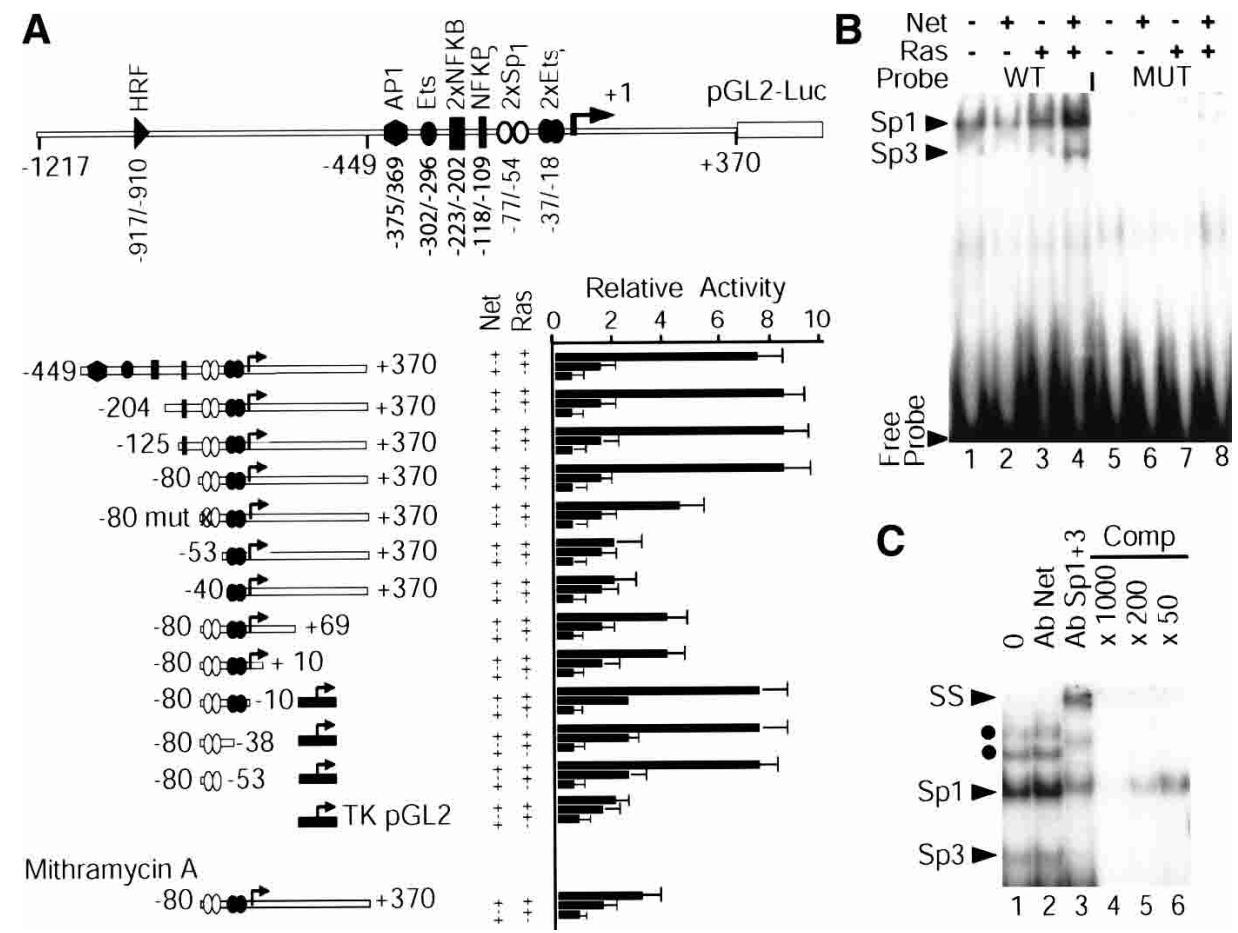

Figure 5. Analysis of Net + Ras activation of the VEGF promoter. (A) Transfection assays with VEGF promoter reporters. The top diagram illustrates the mouse VEGF promoter $(-1217$ to +370$)$ upstream from luciferase coding sequences in pGL2-Luc. The locations of several motifs are indicated, including a hypoxia response element (HRF; -917/-910), two Sp1 motifs, and putative binding sites in the -449 to +1 region for AP1 $(-375 / 365)$, Ets $(-302 /-296)$, two NFkBs $(-223 /-202)$, one NFkB $(-118 /-109)$, and two Ets $(-37 /-18)$ determined by MatInspector version 2.2 (Quandt et al. 1995). The deletion mutants contain VEGF promoter sequences in pGL2-Luc or upstream from the TK promoter in pGL2-Luc. Mithramycin A: $100 \mathrm{nM}$ Mithramycin was added after the wash to remove the precipitate. Net and Ras indicate that the transfections contained expression vectors for Ras-V12 and/or Net, as indicated. Relative activities were calculated relative to the transfections with empty expression vectors. Luciferase activities were corrected for variations in $\beta$-galactoside activity expressed from the internal control. (B) EMSA analysis of factors that bind to the Net + Ras-V12 responsive element (Sp1 motifs). Nuclear extracts were prepared from cells transfected with the indicated expression vectors and analyzed by EMSA with wild-type (WT) or mutant (MT) probes. The positions of the Sp1 and Sp3 complexes and the free probe are indicated. $(C)$ Supershift and competition EMSA. Nuclear extracts were prepared from cells transfected with the Ras-V12 and Net expression vectors and analyzed by EMSA with the wild-type VEGF Sp1 motif probe. The incubations also contained antibodies against Net (\#375), Sp1 and Sp3, or the indicated excess of wild-type cold probe. The Sp1, Sp3, supershifted (SS), and minor complexes (0) are indicated. 
(data not shown). Deletions downstream from the start site were made in the context of the -80 construct. Deletion to +69 or +10 decreased activation, but the remaining activity was still significantly higher than mutants lacking the two Sp1 motifs $(-53$ and -40 to +370$)$. These results suggest that the $-80 /-53$ region containing Sp1 motifs mediates Net + Ras-V12 activation. To investigate this possibility further, small fragments from around the Sp1 motifs were inserted upstream from the heterologous thymidine kinase promoter in pGL2. Reporters with sequences from -80 to $-10,-80$ to -38 , and -80 to -53 were significantly stimulated by Net + RasV12 compared to the TK promoter alone. These results show that the Sp1 motifs of the VEGF promoter are sufficient to mediate Net + Ras-V12 activation. To confirm these observations, we used Mithramycin A, which was reported to be a specific inhibitor of Sp1 (Gambari et al. 2000; Marinovic et al. 2002). Net + Ras-V12 activation of the VEGF promoter was significantly inhibited by 100 nM Mithramycin A (100 nM was determined to be optimum by titration, and similar concentrations have been used in other reports; Marinovic et al. 2002). The different experiments were repeated in two different cell lines, with similar results (NIH3T3 and CHO-D; data not shown). Overall, these results suggest that $\mathrm{Sp} 1$ may mediate Net + Ras-V12 activation of the VEGF promoter.

We used electrophoretic mobility shift assays (EMSAs) to identify the factors that bind to the Sp1 motifs. Nuclear extracts of NIH3T3 cells transfected with the Net and Ras-V12 expression vectors were analyzed with a probe spanning the $S p 1$ motifs $(-79$ to -51$)$. Two complexes were detected that were putatively identified as Sp1 and Sp3 from comparisons with previous reports (Fig. 5B, lane 4; Maeno et al. 2002). The same two bands were also present in nuclear extracts from cells transfected with just the Net vector, just the Ras-V12 vector, or the empty vectors (Fig. 5B, lanes 1-3; the Sp3 band was clearly detected in all conditions in other experiments; data not shown). The bands were specific, because they were not formed with a mutant probe containing mutations in the two Sp1 motifs (wt Sp1 motif, GGGCGGG; mutant, GTTAGGG; see Materials and Methods) and they were competed with excess cold competitor (Fig. 5C, lanes 4-6). The Sp1- and Sp3-labeled bands were supershifted with antibodies against $\mathrm{Sp} 1+\mathrm{Sp} 3$ (Fig. 5C, lanes 1-3; as expected, the Sp1 antibody displaced only the Sp1 band and the Sp3 antibody only the Sp3 band; data not shown). In addition, several minor bands were detected that migrated more slowly than Sp1 and that were supershifted with the Sp1 + Sp3 antibodies (Fig. 5C, indicated by dots, lanes 1-3; similar higher mobility complexes have been detected by others: Maeno et al. 2002). None of the bands were supershifted by Net antibodies (Fig. 5C, lane 2, \#375) that have been shown to supershift Net in EMSA experiments (Maira et al. 1996), suggesting that the complexes do not contain Net. These results show that $S p 1$ and $S p 3$ are the principle factors that bind to the Sp1 motifs in the presence of Net + RasV12, and they suggest that activated P-Net stimulates VEGF promoter activity through effects on Sp1 and Sp3.
Coexpression of P-Net and VEGF in different human tumors

The above studies in model systems suggest that in human tumors MAP-kinase activation would lead to activation of Net by phosphorylation and increased expression of VEGF. To investigate this possibility, we used IHC to investigate P-Net and VEGF expression in five cases of Kaposi's sarcoma, seven of head and neck squamous cell carcinoma (HNSSC), and 12 of prostate cancer. In all cases, we observed coexpression of P-Net and VEGF in tumor cells (Fig. 6). In Kaposi's sarcoma, which undergoes a high rate of angiogenesis driven by VEGF and other cytokines, we detected high levels of P-Net, VEGF, and P-ERK /activated ERK1/2 that phosphorylates and activates Net), in similar patterns in cells with transformed endothelial morphology, but not in the cells that form the vessel walls (Fig. 6A-C). In hypopharyngeal HNSSC (Fig. 6D-F), P-Net, VEGF, and P-ERK were found to be highly expressed in tumor cells but not in surrounding stromal cells and adjacent normal glandular epithelium. In histologically normal tissue from adjacent tissue (uvula) of the same patients, there was no specific staining for P-ERK, P-Net, or VEGF in the basal layer of the epidermis or in the secretory epithelium of the salivary glands (Fig. 6G-I, arrowheads; some weak nonspecific staining was observed in the upper differentiated layers of the epidermis). Similar results were obtained with another Net-phospho-specific antibody (1F12; data not shown). In the prostate cancer cases (Fig. $6 \mathrm{~J}-\mathrm{O})$, the epithelium of nonmalignant secretory acini did not express VEGF and P-Net, except for some transiently proliferating basal cells (Fig. 6J,K, arrowheads). P-Net and VEGF are highly expressed in transformed cells, including malignant acini and extracapsular extensions of the cancer (Fig. 6L-O, arrows). These results show that P-Net and VEGF are coexpressed in transformed cells in different human tumors.

\section{Discussion}

This study provides strong in vivo and in vitro evidence that Net is a regulator of the angiogenesis switch in the adult. Net is required for VEGF expression in response to growth factors and oncogenes that activate angiogenesis and MAP kinase signaling cascades. Net is phosphorylated and activated by these inducers of angiogenesis. Activated P-Net stimulates VEGF expression through a mechanism that probably involves Sp1, a major regulator of VEGF expression.

We have shown that endogenous Net is phosphorylated on critical amino acids in response to FGF-2, KSHV-GPCR, and Ras-V12. Phosphorylation of the Cdomain converts Net from a repressor to an activator of transcription (Criqui-Filipe et al. 1999; Ducret et al. 2000). FGF-2, KSHV-GPCR, and Ras-V12 have been shown to have important roles in angiogenesis (Gerwins et al. 2000; Kerbel and Folkman 2002), showing that molecules involved in angiogenesis can regulate Net. P-Net is detected in keratinocytes and mononuclear cells dur- 

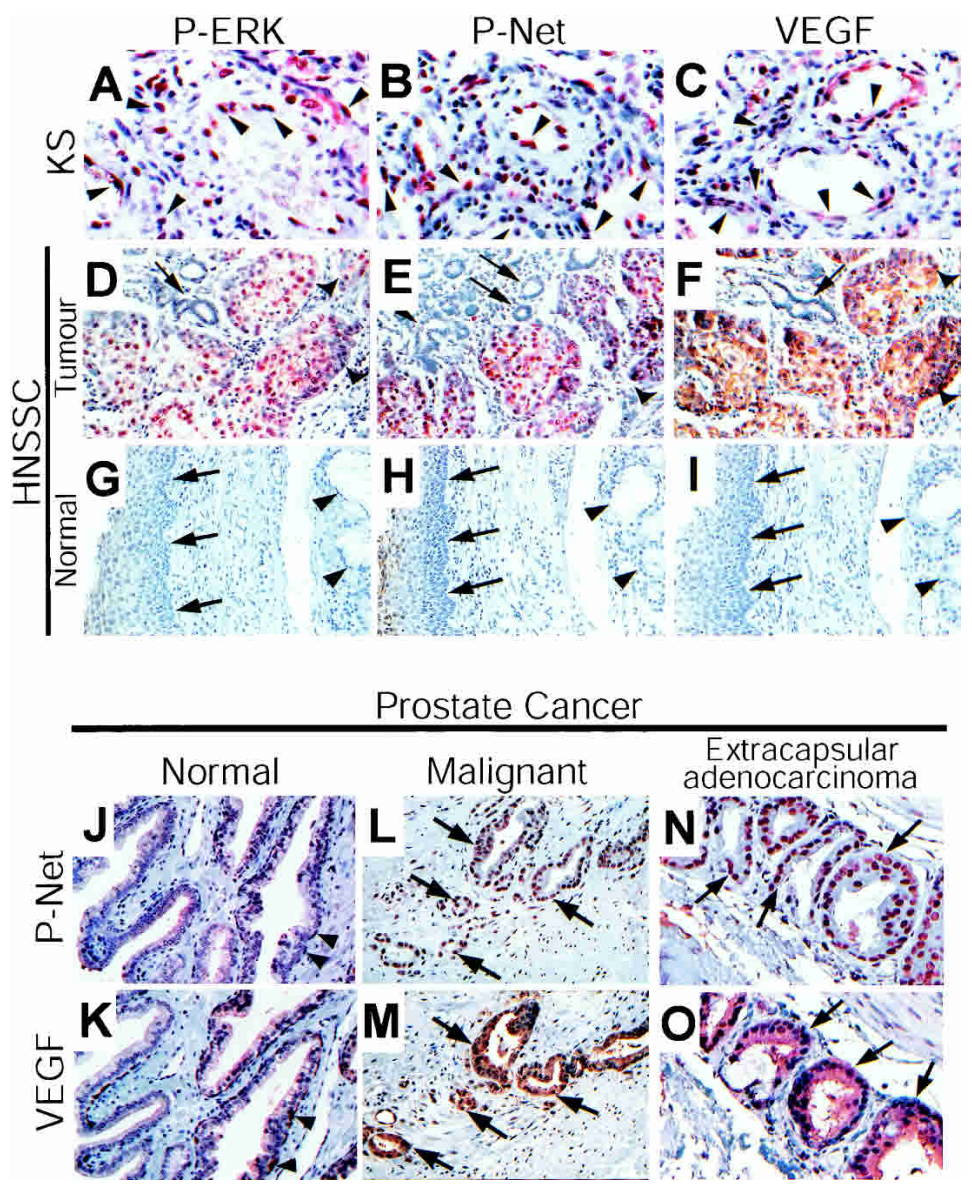

Figure 6. VEGF and P-Net expression (brown staining) in tumors. $(A-C)$ Kaposi's sarcoma. P-ERK1/2 $(A)$, P-Net $(B)$, and VEGF $(C)$ are detected in transformed cells (arrowheads). (D-I) Head and neck squamous cell carcinoma. In tumors, P-ERK1/2 $(D, G)$, P-Net $(E, H)$, and VEGF $(F, I)$ are expressed in tumor cells (arrows, normal glandular epithelium; arrowheads, stromal cells). In histologically normal tissues from the same sections $(G-I)$ there is no detectable expression in the basal layer (arrows) and salivary glands (arrowheads). ( $J-O)$ Prostate cancer. P-Net and VEGF are expressed in normal transiently proliferating cells $(J, K$, arrowheads $)$ and malignant cells $(L-O$, arrows). Magnification: $A-F, J-O, 63 \times$; $G-I, 40 \times$. ing wound healing, and in different transformed cells in human tumors, reflecting activation of Net by poorly defined signaling pathways involved in these processes. In Kaposi's sarcoma and HNSSC, P-Net is detected in similar cells in adjacent sections, which implicates the ERK cascade in Net phosphorylation in these tumors.

Net is required for efficient wound angiogenesis, which could account for the decreased rate of wound closure in net mutant mice. During wound healing, keratinocytes are activated and migrate to cover the wound bed. Inflammatory cells, fibroblasts, and new blood vessels infiltrate the blood clots to form mature stroma and replace the blood clots with granulation tissue (Jacinto et al. 2001; Yamaguchi and Yoshikawa 2001). VEGF is expressed at high levels from 2 to $7 \mathrm{~d}$ after wounding (Fukumura et al. 1998; Kishimoto et al. 2000). VEGF functions as an endothelial cell mitogen and increases vascular permeability, thereby promoting the deposition of the extravascular fibrin matrix. At early stages of healing, VEGF is mainly generated by keratinocytes at wound edges, whereas at later stages it is also produced by the granulation tissue (Brown et al. 1992; Fukumura et al. 1998; Kishimoto et al. 2000). VEGF is possibly upregulated by FGF-2 produced by injured cells (Martin 1997). We found that P-Net is expressed in cells that express VEGF. Early after wounding, P-Net is detected at wound edges in keratinocytes that express VEGF, but not in adjacent normal skin that does not express VEGF. Interestingly, in normal skin, net RNA can be detected in the epidermis and hair follicles, and low levels of PNet are detectable in hair follicles and epidermis (data not shown). VEGF is also expressed in growing hair follicles and at low levels in the epidermis (Kishimoto et al. 2000). Later during healing, mononuclear cells that contribute to the formation of granulation tissue express high levels of P-Net and VEGF, and become the principal cells that express these two molecules. VEGF expression is impaired in keratinocytes and mononuclear cells of the wound in $n e t^{\delta / \delta}$ mice, indicating that Net is required for VEGF up-regulation. The same cells express P-Net and VEGF, suggesting that P-Net regulates VEGF expression in response to inducing signals. Defects in VEGF production have previously been associated with impaired wound healing (Frank et al. 1995).

VEGF-dependent angiogenesis and capillary hyperpermeability are important in the adult animal, in the uterus and corpus luteum during the female reproductive cycle (Chakraborty et al. 1995; Halder et al. 2000; Ma et al. 2001), in the kidney (Kaipainen et al. 1993; Peters et al. 1993; Simon et al. 1995), and in the liver (LeCouter et al. 2003). P-Net is up-regulated at sites of VEGF expression, including the stroma of the uterus during the estrous cycle and during pregnancy, the lutein cells of the corpus luteum during pregnancy, the distal 
but not the proximal tubules of the kidney, and hepatocytes surrounding the central vein ( $\mathrm{H}$. Zheng, unpubl.). This correlation between VEGF expression and P-Net expression in various organs suggests that P-Net has a role in VEGF regulation. In net mutant animals, vessel density and VEGF expression are decreased in the stroma of the uterus and in the lutein cells of the ovary during the estrous cycle and pregnancy. Furthermore, VEGF expression is decreased in the kidney. These results show that in wound healing and some physiological processes, angiogenesis and VEGF expression are dependent on Net. However, we do not know to what extent Net may be a general regulator of angiogenesis and VEGF expression.

We have not observed any overt defects in vascularization during development or in adult $n e t^{\delta / \delta}$ mice. Furthermore, stromal but not epithelial cells of the uterus have decreased VEGF levels in net mutant mice (data not shown). There are different explanations for these observations. Net may regulate angiogenesis and VEGF expression in response to specific signals in some defined situations. A complex balance of positive and negative factors regulates angiogenesis, and a variety of factors have been shown to regulate adult angiogenesis but to have no effect during development (Carmeliet and Jain 2000; Rossant and Howard 2002). Established vasculature in the adult is more stable and is regulated by different mechanisms compared to embryonic development. VEGF is regulated by many factors, including cytokines, growth factors, hypoxia, differentiation, and transformation, and there are multiple routes to VEGF induction (Ferrara and Davis-Smyth 1997; Kerbel and Folkman 2002; Mazure et al. 2003). We have shown that Net in the presence of Ras-V12 activates VEGF expression through a mechanism involving $\mathrm{Sp} 1$ in cell culture, raising the possibility that Net has a specific role in this particular pathway in different processes in the animal. There could also be compensation for Net functions by related factors (Elk-1 and Sap-1) in net mutant animals, and experiments in double, triple, and conditional knockout mice could be used to study this possibility. Net mutant mice develop chylothorax, a phenotype associated with the lymphatic system (Ayadi et al. 2001b). VEGF as well as VEGF-C are required for lymphangiogenesis (Lymboussaki et al. 1999; Nagy et al. 2002), raising the possibility that altered expression of VEGF may lead to the defect observed in Net mutant mice. Furthermore, the VEGF-C promoter contains an Sp1 element (Chilov et al. 1997), suggesting that Net may also regulate VEGF-C expression, and this may be a link with the phenotype.

Kaposi's sarcomas (KS) are cancerous angiogenic red skin lesions that are observed mainly in AIDS patients. All forms of KS are associated with infections with the novel herpesvirus KSHV or HHV8. Although many KSVH genes have transforming potential, KSHV-GPCR is the predominant oncogene in KS (Hayward 2003; Montaner et al. 2003). Stable ectopic expression of KSHVGPCR induces focus formation in NIH-3T3 cells, and these cells produce angiogenic lesions resembling KS in nude mice. KSHV-GPCR expression activates ERK and p38 MAP kinase signaling pathways and VEGF expression (Bais et al. 1998). To study the role of Net in tumor angiogenesis, we used KSHV-GPCR-transformed NIH3T3 cells with down-regulated endogenous Net. The tumors lacking Net grew more slowly in nude mice, and were visibly less angiogenic with fewer vessels. Decreased angiogenesis was confirmed by IHC and quantitation of the number of vessels and the total area occupied by vessels. Furthermore, as expected from reduced angiogenesis, the tumors had diminished oxygen tension. These results show that Net is required for angiogenesis induced by KSHV-GPCR-transformed cells. We also showed that KSHV-GPCR expression induces Net phosphorylation through ERK and p38 MAP kinase signaling pathways and increases its transcriptional activity. Down-regulation of Net decreases VEGF expression, showing that Net is required for KSHV-GPCR-induced VEGF expression. Conditioned medium from KSHV-GPCR-expressing cells contains factors that induce microtube formation by HUVECs, principally VEGF (Bais et al. 1998). Down-regulation of Net inhibited the ability of KSHVGPCR conditioned medium to induce microtube formation, and adding VEGF restored this activity. These results show that KSHV-GPCR increases the levels of PNet, leading to augmented VEGF levels. Interestingly, we observed increased P-Net levels in human KS samples, in transformed cells that express VEGF and contain activated P-ERK. Taken together, these results show that Net is required for angiogenesis and VEGF expression by KSHV-GPCR.

A variety of assays have been used to study angiogenesis, which are more or less complex. The complex assays represent angiogenesis more faithfully, but the mechanisms involved are poorly understood. The simpler assays are more controlled, but only partially reproduce the process (Jain et al. 1997; Auerbach et al. 2003). We used four classical assays, endothelial cell microtube formation (see above), endothelial cell proliferation induced with KSHV-GPCR conditioned medium (data not shown), FGF-2-induced corneal angiogenesis, and aortal sprouting. FGF-2-induced angiogenesis is reduced in the latter two assays using $n e t^{\delta / \delta}$ mutant mice, showing that net is required for FGF-2-induced angiogenesis. FGF-2 induces Net phosphorylation, in smooth muscle cells in the aorta and in fibroblasts in culture. Inhibition of the ERK signaling cascade inhibits FGF-2-induced Net phosphorylation and aortal sprouting. FGF-2 has been shown to up-regulate VEGF in vascular smooth muscle cells (Stavri et al. 1995). VEGF addition restores sprouting in the net mutant mice to the same levels as those in the wild type. These results show that Net is required for FGF-2-induced angiogenesis in several assays, and are consistent with Net having a role in ERK-dependent VEGF expression.

Several of the assays we used involve $n e t^{\delta / \delta}$ mutant mice. The net ${ }^{\delta / \delta}$ mutation was shown to decrease Net activity (Ayadi et al. 2001b). It is highly unlikely that the mutant protein (that lacks the DNA-binding domain) acts in a trans-dominant manner, because heterozygous 
mice have no detectable phenotype. In the present study in other assays, have down-regulated Net with antisense. Furthermore, down-regulation and up-regulation of Net have converse effects on VEGF expression. It is unlikely that the consistent conclusions are due to undetected artifacts in the different experiments.

We investigated the mechanisms by which Net regulates VEGF expression, using transfection assays and EMSA in fibroblasts. Net expression markedly increases Ras-V12 activation of VEGF promoter activity and endogenous VEGF expression. Conversely, when we downregulated endogenous Net with net-antisense, VEGF promoter activity in the presence of Ras-V12 was impaired (data not shown). Elevated VEGF levels were detected only in the transfected cells, indicating that the mechanism does not involve secretion of inducers of VEGF expression, which would be expected to increase VEGF expression in neighboring nontransfected cells. A small region of the mouse promoter $(-80$ to -53$)$ is sufficient to mediate Net + Ras-V12 activation. These sequences specifically bind $\mathrm{Sp} 1$ and to a lesser extent Sp3 in EMSA experiments with extracts from Net + Ras-V12-transfected cells. Mithramycin A, which is considered to be a specific inhibitor of Sp1 (Gambari et al. 2000; Marinovic et al. 2002), impairs Net + Ras-V12 activation of the promoter. Net is activated by Ras-V12 expression through phosphorylation by an ERK-dependent pathway. These results indicate that activated P-Net augments VEGF expression through a mechanism that probably involves Sp1 and Sp3. However, we detected additional minor complexes with EMSA, indicating that other factors may also be involved. AP2 and Egr1 have been shown to bind to the related region of the human promoter (Gille et al. 1997).

Sp1 and HIF1 were shown to be two major regulators of VEGF expression, in response to MAPK signaling pathways and hypoxia (Ferrara and Davis-Smyth 1997; Mazure et al. 2003). The Sp1 element is regulated independently of HIF1 by a large number of factors, including fluid shear stress (Urbich et al. 2003), oxidative stress (Sen et al. 2002; Schafer et al. 2003), interferon $\alpha$ (von Marschall et al. 2003), retinoic acid (Maeno et al. 2002), HPV16 E6 (Lopez-Ocejo et al. 2000), p73 (Salimath et al. 2000), p53 (Zhang et al. 2000; Pal et al. 2001), endotoxin (Sakuta et al. 2001), VHL (Mukhopadhyay et al. 1997), and PDGF (Finkenzeller et al. 1997). The mechanisms of regulation are far from being resolved, but they include protein-protein interactions and stability (Mukhopadhyay et al. 1997), increased binding due to phosphorylation (Milanini-Mongiat et al. 2002; Reisinger et al. 2003), and increased synthesis (Maeno et al. 2002). Sp1 is also regulated by glycosylation and acetylation (Bouwman and Philipsen 2002). The precise mechanisms of P-Net regulation through the $\mathrm{Sp} 1$ elements will require further investigation. We did not detect Net by supershift in EMSA, suggesting that Net is not in the complexes that form on the responsive element, at least in the conditions tested. In some experiments we observed a small increase in the Sp1 complex in EMSA with extracts from $\mathrm{Net}+\mathrm{Ras}-\mathrm{V} 12$-transfected cells, raising the possibility that there could be effects on the binding affinity, degradation, or synthesis of Sp1. Clearly an important future goal is to establish the mechanisms by which many different factors regulate VEGF expression through the Sp1binding element of the VEGF promoter.

Many cancer cells acquire the ability to synthesize growth factors that induce the switch and maintain abnormally activated angiogenesis (Hanahan and Folkman 1996). In several types of human tumor, we detected high levels of phospho-ERK, phospho-Net, and VEGF in the same group of transformed cells, but not in adjacent normal epithelial and stromal cells. We conclude from this study that the Net transcription factor regulates angiogenesis and VEGF expression in response to growth factors and oncogenes. Our findings provide a new and important link in understanding the crucial upstream events in the angiogenic process.

\section{Materials and methods}

\section{Recombinants}

We used pCEFL-KSHV-GPCR and control pCEFL (Bais et al. 1998); p601D-antisense-net, pTL2-Net, pCMV LacZ (Giovane et al. 1994); pHa-Ras-V12 and control p $\Delta$ Ras (Wasylyk et al. 1987); pSG5-puromycin (IGBMC core facility); pEGFP-N1-antinet, Net cDNA in the $3^{\prime}-5^{\prime}$ orientation between the XhoI and BamHI sites of pEGFP-N1 (Clontech); TD-Net, [pTL2-Net (219409) as described in Maira et al. (1996)]; and mouse VEGF-Luc reporters $(-1217 /+370$ and $-449 /+370$; Shima et al. 1996). The VEGF promoter reporters with $5^{\prime}(-204,-125,-80,-80$ mut, $-53,-40 /+370)$ and $3^{\prime}(-80 /+69,-80 /+10)$ deletions were generated by subcloning MluI/BgIII PCR fragment in the corresponding sites of pGL2 basic and sequenced. The -80 mut is derived from the -80 construct, and has a -73 GGGGCGGG -66 to CTCGAGGG mutation in the upstream Sp1 motif. TK-pGL2 and its derivatives with the $-80 /-10,-80 /-38$, and $-80 /-53$ VEGF sequences upstream were prepared in two steps. Oligonucleotides with $5^{\prime} \mathrm{SphI}$ and $3^{\prime} \mathrm{XbaI}$ sites were kinased and ligated into pBLTKCat4 (Criqui-Filipe et al. 1999), and the PVuII-BgIII fragments containing the VEGF promoter elements and the TK promoter were transferred into the SmaI-BgIII sites of pGL2 Basic and sequenced.

\section{Cell culture}

Transfections in NIH3T3 for phosphorylation, promoter activities, VEGF peptide measurements, and conditioned medium: NIH3T3 cells were transfected by the calcium phosphate technique (Maira et al. 1996) with $0.5 \mu \mathrm{g}$ pCEFL-KHSV-GPCR (pCEFL as control) or $0.5 \mu \mathrm{g}$ pRASCTBx2 (Ras-V12) (p $\Delta$ Rsa as control), $1 \mu \mathrm{g}$ p601D-antisense-net (p601D as control). Following the washes to remove the transfection reagent, the cells were cultured in $7 \%$ FCS for $24 \mathrm{~h}$ (phosphorylation by Ras-V12 and GPCR; Fig. 4A), 0.05\% FCS for 36 h (VEGF expression; Fig. $4 \mathrm{C}$ ), or $0.5 \%$ FCS for $48 \mathrm{~h}$ (microtube-forming assay; Fig. 3D-I). From $2 \mathrm{~mL}$ medium, $1 \mathrm{~mL}$ was used for the microtube-forming assays and $50 \mu \mathrm{L}$ for the VEGF ELISA assays (mouse-VEGF Quantikine kit, R\&D Systems). VEGF values were corrected for cell number.

GPCR transformed clones: NIH3T3 cells were transfected by the calcium phosphate technique with $0.5 \mu \mathrm{g}$ pCEFL-KSHVGPCR and selected with $750 \mu \mathrm{g} / \mathrm{mL}$ G418. Stable clones were expanded and analyzed by reverse transcriptase PCR (RT-PCR) 
for the expression of GPCR. Transformed clones that expressed GPCR were retransfected with pSG5-puromycin and pEGFPN1-anti-net or pEGFP-N1 and selected with $750 \mu \mathrm{g} / \mathrm{mL}$ G418 and $2 \mu \mathrm{g} / \mathrm{mL}$ puromycin (Sigma). Individual clones and pools were expanded and analyzed by Western blotting (Fig. 2A).

Promoter activity measurements, Western blots, ICC, and EMSA of transfected cells: NIH3T3 cells were transfected with the calcium phosphate technique $[2 \mu \mathrm{g}$ pTL2Net, $0.5 \mu \mathrm{g}$ pRasCTBx2 (Ras-V12), 1 ug mouse-VEGF-promoter-Luc constructs, $1 \mu \mathrm{g}$ pCMV LacZ or the corresponding empty vectors in 6-well plates]. After removal of the precipitate, the cells were incubated in medium containing $0.05 \%$ FCS for $36 \mathrm{~h}$, and extracts were prepared for the Western blots and luciferase assays. Luciferase activities, from three experiments with two plasmid preparations, were corrected for $\beta$-galactosidase activity expressed from the internal control and used to calculate fold activation relative to control vectors.

\section{Western blots}

Transfections: NIH3T3 cells were transfected with expression vectors for GPCR or Ras-V12, or their controls (pCEFL and $\mathrm{p} \Delta$ Ras, respectively). Three hours after the wash, the cells were treated with $10 \mu \mathrm{M}$ SB203580 (Alexis) or $10 \mu \mathrm{M}$ U0126 (Promega) for $30 \mathrm{~min}$, and, after a further $6-8 \mathrm{~h}$ in Dulbecco $+7 \%$ FCS, the cells were harvested for SDS-PAGE and Western-blotted with antibodies against phospho-Ser 365 Net (2F3; Ducret et al. 2000), phosphorylated ERK (V8031, Promega), and TBP.

FGF-2 treatment: NIH3T3 cells were pretreated with SB203580 and U0126 as described above, washed, treated with $40 \mathrm{ng} / \mathrm{mL}$ FGF-2 (R\&D Systems) for $15 \mathrm{~min}$, harvested, and analyzed by SDS-PAGE and Western-blotting as above.

Stable clones: Cell extracts were analyzed by SDS-PAGE and Western blotting with antibodies against endogenous Net (Ab \#375) and Elk-1 (Ab \#512; Giovane et al. 1994).

Endogenous VEGF expression measurements: NIH3T3 cells were transfected with $2 \mu \mathrm{g}$ pTL2-Net and $0.5 \mu \mathrm{g}$ pRasCTBx2 (Ras-V12) per well and, $36 \mathrm{~h}$ after the wash, cell extracts were analyzed by SDS-PAGE and Western blotting [anti-phospho-Net (2F3), goat anti-VEGF (R\&D), and mouse anti-TBP (IGBMC)].

\section{Immunohistochemistry}

Published methods for histology and immunostaining were used (Bergers et al. 1999; Holash et al. 1999). Eight-micrometer adjacent paraffin sections were rehydrated, demasked in $0.01 \mathrm{M}$ citrate for $60 \mathrm{~min}$ at $94^{\circ} \mathrm{C}$, cooled for $60 \mathrm{~min}$, incubated with primary antibodies [phospho-ERK (\#9101, Cell Signalling), 1/50 in TBST; human VEGF (AF-283-NA, R\&D Systems), 1/200 in PBST; phospho-Net, (2F3 and 1F12, IGBMC), 1/500 in PBST; CD31 (01951A, Pharmingen), 1/50 in PBST] for $3 \mathrm{~h}$ at $25^{\circ} \mathrm{C}$ followed by overnight at $4^{\circ} \mathrm{C}$, and stained with the VECTASTAIN Elite ABC kit (Vector Laboratories). For VEGF detection, the same conditions were used for the sections from the $n e t^{\delta / \delta}$ as for the wild-type mice. For P-Net and VEGF colocalization, 10- $\mu \mathrm{m}$ cryostat sections were fixed with $2 \%$ PFA at $4^{\circ} \mathrm{C}$ for $10 \mathrm{~min}$. They were incubated with antibodies against P-Net (2F3 and $1 \mathrm{~F} 12,1: 50$ ) for $2 \mathrm{~h}$ at room temperature and at $4^{\circ} \mathrm{C}$ overnight, followed by FITC-conjugated anti-mouse (Jackson, 1:500) at room temperature for $1 \mathrm{~h}$. The slides were then incubated with antibodies against VEGF (Santa Cruz, sc-507, 1:50) for $2 \mathrm{~h}$ at room temperature and at $4^{\circ} \mathrm{C}$ overnight, followed by Texas-Red conjugated anti-rabbit (Jackson, 1:500) at room temperature for $1 \mathrm{~h}$. For hypoxic tension detection, $10 \mu \mathrm{M}$ EF5 (Lord et al. 1993) was injected into mice bearing tumors (1 mg per mouse) $4 \mathrm{~h}$ before sacrifice. Ten-micrometer cryostat sections were stained with anti-EF5 antibody coupled to Cy5, and analyzed with a computer-controlled fluorescence microscope and digital camera, with identical exposure. EF5, the anti-EF5 antibody coupled to Cy5, the controls, and the protocols were obtained from The Radiation Oncology Imaging Service Center, University of Pennsylvania.

\section{Immunocytochemistry}

NIH3T3 cells $\left(1 \times 10^{5}\right.$ cells in 6 -well plates $)$ grown on coverslips were transfected in the same conditions as for the VEGF-promoter luciferase assays. Forty-eight hours after the precipitate was washed off, the cells were fixed for $10 \mathrm{~min}$ with $2 \%$ PFA in PBS on ice and then permeabilized with $0.1 \%$ Triton-X100 in $0.1 \%$ sodium citrate for $15 \mathrm{~min}$ at room temperature. The coverslips were washed with PBS, blocked with PBS containing $3 \%$ bovine serum albumin (BSA) for $30 \mathrm{~min}$, incubated with the first antibody [anti-P-Net (2F3) mouse monoclonal diluted 1:600 (antibodies were diluted in PBS containing $0.3 \% \mathrm{BSA})]$ for $2 \mathrm{~h}$ at $37^{\circ} \mathrm{C}$, washed five times, and then incubated with the second antibody [rabbit polyclonal anti-VEGF (Santa Cruz) 1:200] for 2 $\mathrm{h}$ at $37^{\circ} \mathrm{C}$. They were washed five times with $0.2 \%$ Tween-20 in PBS and incubated for $60 \mathrm{~min}$ at $37^{\circ} \mathrm{C}$ with FITC-conjugated anti-mouse IgG (diluted 1:100) and Texas-Red-conjugated antirabbit (diluted 1:250). The cells were stained with $0.5 \mathrm{mg} / \mathrm{mL}$ DAPI for $2 \mathrm{~min}$ and washed five times with PBS-Tween. The coverslips were mounted on microscope slides using VECTRASHIELD mounting medium for fluorescence and examined by confocal microscopy.

\section{Wound healing and tumor angiogenesis}

Wound healing: The protocols were adapted from Ortega et al. (1998). After applying an 8-mm-diam full-thickness skin wound in 4-week-old male mice, wound surfaces were measured and photographed every $2 \mathrm{~d}$, with and without removing the clot. After the wounds had healed totally, the same mice were used to generate independent wounds (more than $1 \mathrm{~cm}$ from the first wounds) that were used for histological analysis 2 or $6 \mathrm{~d}$ after wounding.

Tumor angiogenesis: Stably KSHV-GPCR-transformed cells $\left(3 \times 10^{5} / 200 \mu \mathrm{L}\right.$ PBS/animal) were detached with $3 \mathrm{mM}$ EDTA in PBS, resuspended in PBS, and injected subcutaneously in the left flank of 8 -week-old female BALB/c nu/nu mice. The smaller and larger tumor diameters were measured every $2 \mathrm{~d}$ with calipers, and tumor volumes were calculated $[\mathrm{V}=4 / 3 \times \pi \times(1 /$ $2 \times$ smaller diameter $)^{2} \times(1 / 2 \times$ larger diameter $\left.)\right]$. Sixteen days after injection the mice were sacrificed, and $10-\mu \mathrm{m}$ paraffin tumor sections were prepared for immunohistological analysis. To measure the proportion of the area occupied by vessels, and the number of vessels, we analyzed five representative sections per tumor, and three tumors for each clone. Four randomly selected $\times 100$ fields for each section were analyzed with a computercontrolled microscope and digital camera. Morphometric analysis (number and size of vessels in tumor mass) was performed with Nsurfx software (Baldock et al. 1997). The vessels were recognized by their dark-gray stained walls. The number of vessels is the total number of individual vessels that were observed. The size of each vessel is the total area of its lumen and walls. The total vessel-occupied area is the sum of the areas occupied by all of the vessels.

\section{Angiogenesis models in vitro}

For the mouse aortic ring angiogenesis assay (Nicosia and Ottinetti 1990; Rohan et al. 2000), thoracic aortas were excised from 
four pairs of 2- to 4-week-old net $t^{\delta / \delta}$ mice and their wild-type littermates, washed, cut into 1 -mm-long sections, and placed upright in $400 \mu \mathrm{L}$ of Matrigel (Becton Dickinson Labware) that was allowed to solidify for $30 \mathrm{~min}$. The sections were incubated for $24 \mathrm{~h}$ in EGM-2 (Clonetic) followed by $3 \mathrm{~d}$ in EBM (Clonetic) with $40 \mathrm{ng} / \mathrm{mL}$ FGF-2 (R\&D Systems) alone or combined with $60 \mathrm{ng} / \mathrm{mL}$ VEGF (R\&D Systems) for rings from mutant mice. The microvessel sprouts were examined on day 4 . After photography, frozen sections were prepared from the gels containing the rings and sprouts. For the corneal micropocket assay (Kenyon et al. 1996), Hydron (Sigma) pellets containing $90 \mathrm{ng}$ FGF-2 and 45 ng sucrafate were implanted in corneal pockets on both eyes of four pairs of 4-week-old $n e t^{\delta / \delta}$ mice and their wildtype littermates. The eyes were examined by biomicroscopy after 3-6 d. For the microtubule formation assay (Bais et al. 1998), 24-well plates were coated with $120 \mu \mathrm{L}$ per well of Matrigel (Becton Dickinson Labware) for $30 \mathrm{~min} 37^{\circ} \mathrm{C}$. HUVEC cells $\left(10^{4}\right.$ in $0.5 \%$ FCS $)$ were allowed to attach, the medium was removed, conditioned medium was added $(1 \mathrm{~mL} /$ well, see Cell Culture), and after $24 \mathrm{~h}$ the plates were photographed. For antiVEGF antibody inhibition and VEGF stimulation, conditioned medium was preincubated with $0.2 \mu \mathrm{g} / \mathrm{mL}$ of anti-mouse-VEGF polyclonal antibody (R\&D Systems) or $10 \mathrm{ng} / \mathrm{mL}$ of recombinant human VEGF (R\&D Systems) for $1 \mathrm{~h}$ at room temperature before putting it on the cells.

\section{Electrophoretic mobility shift assays}

Nuclear extracts were prepared from NIH3T3 cells that had been transfected under the same conditions as for the VEGF promoter luciferase assays. The transfection efficiencies were up to $30 \%$, as measured by the fluorescence of pGFP-C1 (Promega) transfected in control plates. Nuclei were isolated using the rapid micropreparation technique (Andrews and Faller 1991). The nuclear pellets were resuspended in cold Buffer C, and protein was quantified by the Bradford assay. The probes, corresponding to the -79 to -51 sequence of the mouse VEGF promoter (wild type: $5^{\prime}$-GTCCCCGGGGCGGGTCTGGGCGG GGCTTG-3'; Sp1 motif mutant: 5'-GTCCCCGGTTAGGGTC TGGTTAGGGGCTTG-3'), were end-labeled with $\gamma$-[ $\left.{ }^{32} \mathrm{P}\right]$ ATP (Amersham Bio) and purified on $10 \%$ acrylamide gels. The DNA binding reactions were performed with $5 \mu \mathrm{g}$ nuclear protein and $100,000 \mathrm{cpm}\left[{ }^{32} \mathrm{P}\right]$-labeled oligonucleotides for $30 \mathrm{~min}$ in $20 \mu \mathrm{L}$ of binding buffer $\left[10 \mathrm{mM}\right.$ Tris- $\mathrm{HCl}$ at $\mathrm{pH} 7.5,1 \mathrm{mM} \mathrm{MgCl}_{2}, 50$ $\mathrm{mM} \mathrm{NaCl}, 0.5 \mathrm{mM}$ dithiothreitol, $0.5 \mathrm{mM}$ EDTA, 4\% glycerol, $1 \mu \mathrm{g}$ of poly(dI-dC), and $0.2 \%$ NP40]. The specificity controls were the mutant $\mathrm{Sp} 1$ probe and competition reactions in which 50-, 200-, and 1000-fold molar excesses of unlabeled Sp1 oligonucleotides were added to the binding reaction $10 \mathrm{~min}$ prior to the addition of the radiolabeled probe. For supershift assays, antibodies $[1 \mu \mathrm{g}$ per reaction of mouse anti-Sp1 and anti-Sp3 protein (Santa Cruz Biotechnology) and mouse anti-Net \#375 [Giovane et al. 1994)] were added to the reaction mixture for 10 min at $4^{\circ} \mathrm{C}$ before the addition of the probe.

Electrophoresis was performed on $5 \%$ polyacrylamide gels in $0.25 \times$ TBE for $4 \mathrm{~h}$ at $280-300 \mathrm{~V} / 10-15 \mathrm{~mA}$ at $4^{\circ} \mathrm{C}$.

\section{Acknowledgments}

We thank Dr. H. Klocker for materials, help and advice; Drs. E.A. Mesri and P.A. D'Amore for recombinants; Dr. Mei Li for helpful discussions; the IGBMC core facilities for help and support; and BioAvenir (Aventis, Rhone-Poulenc), the Centre National de la Recherche Scientifique, the Institut National de la Santé et de la Recherche Médicale, the Hôpital Universitaire de
Strasbourg, the Association pour la Recherche sur le Cancer, the Fondation pour la Recherche Médicale, the Ligue Nationale Française contre le Cancer (Equipe labellisée), the Ligue Régionale (Haut-Rhin) contre le Cancer, the Ligue Régionale (BasRhin) contre le Cancer, the EU (FP5 project QLK6-2000-00159), and the German Cancer Association for financial assistance.

The publication costs of this article were defrayed in part by payment of page charges. This article must therefore be hereby marked "advertisement" in accordance with 18 USC section 1734 solely to indicate this fact.

\section{References}

Andrews, N.C. and Faller, D.V. 1991. A rapid micropreparation technique for extraction of DNA-binding proteins from limiting numbers of mammalian cells. Nucleic Acids Res. 19: 2499.

Arbiser, J.L., Moses, M.A., Fernandez, C.A., Ghiso, N., Cao, Y., Klauber, N., Frank, D., Brownlee, M., Flynn, E., Parangi, S., et al. 1997. Oncogenic H-ras stimulates tumor angiogenesis by two distinct pathways. Proc. Natl. Acad. Sci. 94: 861866.

Auerbach, R., Lewis, R., Shinners, B., Kubai, L., and Akhtar N. 2003. Angiogenesis assays: A critical overview. Clin. Chem. 49: $32-40$.

Ayadi, A., Suelves, M., Dolle, P., and Wasylyk, B., 2001a. Net, an Ets ternary complex transcription factor, is expressed in sites of vasculogenesis, angiogenesis, and chondrogenesis during mouse development. Mech. Dev. 102: 205-208.

Ayadi, A., Zheng, H., Sobieszczuk, P., Buchwalter, G., Moerman, P., Alitalo, K., and Wasylyk B. 2001b. Net-targeted mutant mice develop a vascular phenotype and up-regulate egr1. EMBO J. 20: 5139-5152.

Bais, C., Santomasso, B., Coso, O., Arvanitakis, L., Raaka, E.G., Gutkind, J.S., Asch, A.S., Cesarman, E., Gershengorn, M.C., Mesri, E.A., et al. 1998. G-protein-coupled receptor of Kaposi's sarcoma-associated herpesvirus is a viral oncogene and angiogenesis activator. Nature 391: 86-89 (published erratum appears in 392: 210).

Baldock, R.A., Verbeek, F.J., and Vonesch, J.L. 1997. 3-D Reconstructions for graphical databases of gene expression. Sem. Cell and Dev. Biol. 8: 499-507.

Bergers, G., Javaherian, K., Lo, K.M., Folkman, J., and Hanahan, D. 1999. Effects of angiogenesis inhibitors on multistage carcinogenesis in mice. Science 284: 808-812.

Boshoff, C. and Weiss, R.A. 1998. Kaposi's sarcoma-associated herpesvirus. Adv. Cancer Res. 75: 57-86.

Bouwman, P. and Philipsen, S. 2002. Regulation of the activity of Spl-related transcription factors. Mol. Cell Endocrinol. 195: 27-38.

Brown, L.F., Yeo, K.T., Berse, B., Yeo, T.K., Senger, D.R., Dvorak, H.F., and van de Water, L. 1992. Expression of vascular permeability factor (vascular endothelial growth factor) by epidermal keratinocytes during wound healing. $J$. Exp. Med. 176: 1375-1379.

Carmeliet, P. and Jain, R.K. 2000. Angiogenesis in cancer and other diseases. Nature 407: 249-257.

Chakraborty, I., Das, S.K., and Dey, S.K. 1995. Differential expression of vascular endothelial growth factor and its receptor mRNAs in the mouse uterus around the time of implantation. J. Endocrinol. 147: 339-352.

Chilov, D., Kukk, E., Taira, S., Jeltsch, M., Kaukonen, J., Palotie, A., Joukov, V., and Alitalo, K. 1997. Genomic organization of human and mouse genes for vascular endothelial growth factor C. J. Biol. Chem. 272: 25176-25183. 
Criqui-Filipe, P., Ducret, C., Maira, S.M., and Wasylyk, B. 1999. Net, a negative Ras-switchable TCF, contains a second inhibition domain, the CID, that mediates repression through interactions with $\mathrm{CtBP}$ and de-acetylation. $E M B O ~ J$. 18: 3392-3403.

Ducret, C., Maira, S.M., Lutz, Y., and Wasylyk, B. 2000. The ternary complex factor net contains two distinct elements that mediate different responses to MAP kinase signalling cascades. Oncogene 19: 5063-5072.

Ferrara, N. and Davis-Smyth, T. 1997. The biology of vascular endothelial growth factor. Endocr. Rev. 18: 4-25.

Finkenzeller, G., Sparacio, A., Technau, A., Marme, D., and Siemeister, G. 1997. Sp1 recognition sites in the proximal promoter of the human vascular endothelial growth factor gene are essential for platelet-derived growth factor-induced gene expression. Oncogene 15: 669-676.

Forsythe, J.A., Jiang, B.H., Iyer, N.V., Agani, F., Leung, S.W., Koos, R.D., and Semenza, G.L. 1996. Activation of vascular endothelial growth factor gene transcription by hypoxia-inducible factor 1. Mol. Cell Biol. 16: 46044613.

Frank, S., Hubner, G., Breier, G., Longaker, M.T., Greenhalgh, D.G., and Werner, S. 1995. Regulation of vascular endothelial growth factor expression in cultured keratinocytes. Implications for normal and impaired wound healing. J. Biol. Chem. 270: 12607-12613.

Fukumura, D., Xavier, R., Sugiura, T., Chen, Y., Park, E.C., Lu, N., Selig, M., Nielsen, G., Taksir, T., Jain, R.K., et al. 1998. Tumor induction of VEGF promoter activity in stromal cells. Cell 94: 715-725.

Gambari, R., Feriotto, G., Rutigliano, C., Bianchi, N., and Mischiati, C. 2000. Biospecific interaction analysis (BIA) of lowmolecular weight DNA-binding drugs. J. Pharmacol. Exp. Ther. 294: 370-377.

Gerwins, P., Skoldenberg, E., and Claesson-Welsh, L. 2000. Function of fibroblast growth factors and vascular endothelial growth factors and their receptors in angiogenesis. Crit. Rev. Oncol. Hematol. 34: 185-194.

Gille, J., Swerlick, R.A., and Caughman, S.W. 1997. Transforming growth factor-alpha-induced transcriptional activation of the vascular permeability factor (VPF/VEGF) gene requires AP-2-dependent DNA binding and transactivation. EMBO $J$. 16: $750-759$.

Giovane, A., Pintzas, A., Maira, S.M., Sobieszczuk, P., and Wasylyk, B. 1994. Net, a new ets transcription factor that is activated by Ras. Genes \& Dev. 8: 1502-1513.

Grugel, S., Finkenzeller, G., Weindel, K., Barleon, B., and Marme, D. 1995. Both v-Ha-Ras and v-Raf stimulate expression of the vascular endothelial growth factor in NIH 3T3 cells. J. Biol. Chem. 270: 25915-25919.

Halder, J.B., Zhao, X., Soker, S., Paria, B.C., Klagsbrun, M., Das, S.K., and Dey, S.K. 2000. Differential expression of VEGF isoforms and VEGF(164)-specific receptor neuropilin-1 in the mouse uterus suggests a role for $\operatorname{VEGF}(164)$ in vascular permeability and angiogenesis during implantation. Genesis 26: $213-224$.

Hanahan, D. and Folkman, J. 1996. Patterns and emerging mechanisms of the angiogenic switch during tumorigenesis. Cell 86: 353-364.

Hayward, G.S. 2003. Initiation of angiogenic Kaposi's sarcoma lesions. Cancer Cell 3: 1-3.

Holash, J., Wiegand, S.J., and Yancopoulos, G.D. 1999. New model of tumor angiogenesis: Dynamic balance between vessel regression and growth mediated by angiopoietins and VEGF. Oncogene 18: 5356-5362.

Jacinto, A., Martinez-Arias, A., and Martin, P. 2001. Mecha- nisms of epithelial fusion and repair. Nat. Cell Biol. 3: E117E123.

Jain, R.K., Schlenger, K., Hockel, M., and Yuan, F. 1997. Quantitative angiogenesis assays: Progress and problems. Nat. Med. 3: 1203-1208.

Kaipainen, A., Korhonen, J., Pajusola, K., Aprelikova, O., Persico, M.G., Terman, B.I., and Alitalo, K. 1993. The related FLT4, FLT1, and KDR receptor tyrosine kinases show distinct expression patterns in human fetal endothelial cells. $J$. Exp. Med. 178: 2077-2088.

Kenyon, B.M., Voest, E.E., Chen, C.C., Flynn, E., Folkman, J., and D'Amato, R.J. 1996. A model of angiogenesis in the mouse cornea. Invest. Ophthalmol. Vis. Sci. 37: 16251632.

Kerbel, R. and Folkman, J. 2002. Clinical translation of angiogenesis inhibitors. Nat. Rev. Cancer 2: 727-739.

Kishimoto, J., Ehama, R., Ge, Y., Kobayashi, T., Nishiyama, T., Detmar, M., and Burgeson, R.E. 2000. In vivo detection of human vascular endothelial growth factor promoter activity in transgenic mouse skin. Am. J. Pathol. 157: 103-110.

LeCouter, J., Moritz, D.R., Li, B., Phillips, G.L., Liang, X.H., Gerber, H.P., Hillan, K.J., and Ferrara, N. 2003. Angiogenesis-independent endothelial protection of liver: Role of VEGFR-1. Science 299: 890-893.

Lopez-Ocejo, O., Viloria-Petit, A., Bequet-Romero, D., Mukhopadhyay, M., Rak, J., and Kerbel, R.S. 2000. Oncogenes and tumor angiogenesis: The HPV-16 E6 oncoprotein activates the vascular endothelial growth factor (VEGF) gene promoter in a p53 independent manner. Oncogene 19: 46114620.

Lord, E.M., Harwell, L., and Koch, C.J. 1993. Detection of hypoxic cells by monoclonal antibody recognizing 2-nitroimidazole adducts. Cancer Res. 53: 5721-5726.

Lymboussaki, A., Olofsson, B., Eriksson, U., and Alitalo, K. 1999. Vascular endothelial growth factor (VEGF) and VEGF-C show overlapping binding sites in embryonic endothelia and distinct sites in differentiated adult endothelia. Circ. Res. 85: 992-999.

Ma, W., Tan, J., Matsumoto, H., Robert, B., Abrahamson, D.R., Das, S.K., and Dey, S.K. 2001. Adult tissue angiogenesis: Evidence for negative regulation by estrogen in the uterus. Mol. Endocrinol. 15: 1983-1992.

Maeno, T., Tanaka, T., Sando, Y., Suga, T., Maeno, Y., Nakagawa, J., Hosono, T., Sato, M., Akiyama, H., Kishi, S., et al. 2002. Stimulation of vascular endothelial growth factor gene transcription by all trans retinoic acid through Sp1 and Sp3 sites in human bronchioloalveolar carcinoma cells. Am. J. Respir. Cell Mol. Biol. 26: 246-253.

Maira, S.M., Wurtz, J.M., and Wasylyk, B. 1996. Net (ERP/SAP2) one of the Ras-inducible TCFs, has a novel inhibitory domain with resemblance to the helix-loop-helix motif. EMBO J. 15: 5849-5865.

Marinovic, A.C., Zheng, B., Mitch, W.E., and Price, S.R. 2002. Ubiquitin ( $\mathrm{UbC}$ ) expression in muscle cells is increased by glucocorticoids through a mechanism involving Sp1 and MEK1. J. Biol. Chem. 277: 16673-16681.

Martin, P. 1997. Wound healing-Aiming for perfect skin regeneration. Science 276: 75-81.

Mazure, N.M., Brahimi-Horn, M.C., and Pouyssegur, J. 2003. Protein kinases and the hypoxia-inducible factor-1, two switches in angiogenesis. Curr. Pharm. Des. 9: 531-541.

Milanini-Mongiat, J., Pouyssegur, J., and Pages, G. 2002. Identification of two Sp1 phosphorylation sites for $\mathrm{p} 42 / \mathrm{p} 44 \mathrm{mi}-$ togen-activated protein kinases: Their implication in vascular endothelial growth factor gene transcription. J. Biol. Chem. 277: 20631-20639. 
Montaner, S., Sodhi, A., Molinolo, A., Bugge, T.H., Sawai, E.T., He, Y., Li, Y., Ray, P.E., and Gutkind, J.S. 2003. Endothelial infection with KSHV genes in vivo reveals that vGPCR initiates Kaposi's sarcomagenesis and can promote the tumorigenic potential of viral latent genes. Cancer Cell 3: 23-36.

Mukhopadhyay, D., Tsiokas, L., and Sukhatme, V.P. 1995. Wild-type p53 and v-Src exert opposing influences on human vascular endothelial growth factor gene expression. Cancer Res. 55: 6161-6165.

Mukhopadhyay, D., Knebelmann, B., Cohen, H.T., Ananth, S., and Sukhatme, V.P. 1997. The von Hippel-Lindau tumor suppressor gene product interacts with $\mathrm{Sp} 1$ to repress vascular endothelial growth factor promoter activity. Mol. Cell Biol. 17: 5629-5639.

Nagy, J.A., Vasile, E., Feng, D., Sundberg, C., Brown, L.F., Detmar, M.J., Lawitts, J.A., Benjamin, L., Tan, X., Manseau, E.J., et al. 2002. Vascular permeability factor/vascular endothelial growth factor induces lymphangiogenesis as well as angiogenesis. J. Exp. Med. 196: 1497-1506.

Nicosia, R.F. and Ottinetti, A. 1990. Growth of microvessels in serum-free matrix culture of rat aorta. A quantitative assay of angiogenesis in vitro. Lab. Invest. 63: 115-122.

Nicosia, R.F., Lin, Y.J., Hazelton, D., and Qian, X. 1997. Endogenous regulation of angiogenesis in the rat aorta model. Role of vascular endothelial growth factor. Am. J. Pathol. 151: 1379-1386.

Oosthuyse, B., Moons, L., Storkebaum, E., Beck, H., Nuyens, D., Brusselmans, K., Van Dorpe, J., Hellings, P., Gorselink, M., Heymans, S., et al. 2001. Deletion of the hypoxia-response element in the vascular endothelial growth factor promoter causes motor neuron degeneration. Nat. Genet. 28: 131-138.

Ortega, S., Ittmann, M., Tsang, S.H., Ehrlich, M., and Basilico, C. 1998. Neuronal defects and delayed wound healing in mice lacking fibroblast growth factor 2. Proc. Natl. Acad. Sci. 95: 5672-5677.

Pal, S., Datta, K., and Mukhopadhyay, D. 2001. Central role of p53 on regulation of vascular permeability factor/vascular endothelial growth factor (VPF/VEGF) expression in mammary carcinoma. Cancer Res. 61: 6952-6957.

Peters, K.G., De Vries, C., and Williams, L.T. 1993. Vascular endothelial growth factor receptor expression during embryogenesis and tissue repair suggests a role in endothelial differentiation and blood vessel growth. Proc. Natl. Acad. Sci. 90: 8915-8919.

Quandt, K., Frech, K., Karas, H., Wingender, E., and Werner, T. 1995. MatInd and MatInspector: New fast and versatile tools for detection of consensus matches in nucleotide sequence data. Nucleic Acids Res. 23: 4878-4884.

Rak, J., Mitsuhashi, Y., Bayko, L., Filmus, J., Shirasawa, S., Sasazuki, T., and Kerbel, R.S. 1995. Mutant ras oncogenes upregulate VEGF/VPF expression: Implications for induction and inhibition of tumor angiogenesis. Cancer Res. 55: 45754580 .

Reisinger, K., Kaufmann, R., and Gille, J. 2003. Increased Sp1 phosphorylation as a mechanism of hepatocyte growth factor (HGF/SF)-induced vascular endothelial growth factor (VEGF/VPF) transcription. J. Cell Sci. 116: 225-238.

Rohan, R.M., Fernandez, A., Udagawa, T., Yuan, J., and D'Amato, R.J. 2000. Genetic heterogeneity of angiogenesis in mice. FASEB I. 14: 871-876.

Rossant, J. and Howard, L. 2002. Signaling pathways in vascular development. Annu. Rev. Cell Dev. Biol. 18: 541-573.

Sakuta, T., Matsushita, K., Yamaguchi, N., Oyama, T., Motani, R., Koga, T., Nagaoka, S., Abeyama, K., Maruyama, I., Takada, H., et al. 2001. Enhanced production of vascular endothelial growth factor by human monocytic cells stimulated with endotoxin through transcription factor SP-1. I. Med. Microbiol. 50: 233-237.

Salimath, B., Marme, D., and Finkenzeller, G. 2000. Expression of the vascular endothelial growth factor gene is inhibited by p73. Oncogene 19: 3470-3476.

Schafer, G., Cramer, T., Suske, G., Kemmner, W., Wiedenmann, B., and Hocker, M. 2003. Oxidative stress regulates vascular endothelial growth factor-A gene transcription through Sp1and Sp3-dependent activation of two proximal GC-rich promoter elements. J. Biol. Chem. 278: 8190-8198.

Sen, C.K., Khanna, S., Babior, B.M., Hunt, T.K., Ellison, E.C., and Roy, S. 2002. Oxidant-induced vascular endothelial growth factor expression in human keratinocytes and cutaneous wound healing. J. Biol. Chem. 277: 33284-33290.

Sharrocks, A.D. 2001. The ETS-domain transcription factor family. Nat. Rev. Mol. Cell Biol. 2: 827-837.

Shima, D.T., Kuroki, M., Deutsch, U., Ng, Y.S., Adamis, A.P., and D'Amore, P.A. 1996. The mouse gene for vascular endothelial growth factor. Genomic structure, definition of the transcriptional unit, and characterization of transcriptional and post-transcriptional regulatory sequences. J. Biol. Chem. 271: 3877-3883.

Simon, M., Grone, H.J., Johren, O., Kullmer, J., Plate, K.H., Risau, W., and Fuchs, E. 1995. Expression of vascular endothelial growth factor and its receptors in human renal ontogenesis and in adult kidney. Am. J. Physiol. 268: F240-F250.

Stavri, G.T., Zachary, I.C., Baskerville, P.A., Martin, J.F., and Erusalimsky, J.D. 1995. Basic fibroblast growth factor upregulates the expression of vascular endothelial growth factor in vascular smooth muscle cells. Synergistic interaction with hypoxia. Circ. 92: 11-14.

Treisman, R. 1994. Ternary complex factors: Growth factor regulated transcriptional activators. Curr. Opin. Genet. Dev. 4: 96-101.

Urbich, C., Stein, M., Reisinger, K., Kaufmann, R., Dimmeler, S., and Gille, J. 2003. Fluid shear stress-induced transcriptional activation of the vascular endothelial growth factor receptor-2 gene requires Sp1-dependent DNA binding. FEBS Lett. 535: 87-93.

von Marschall, Z., Scholz, A., Cramer, T., Schafer, G., Schirner, M., Oberg, K., Wiedenmann, B., Hocker, M., and Rosewicz, S. 2003. Effects of interferon- $\alpha$ on vascular endothelial growth factor gene transcription and tumor angiogenesis. $J$. Natl. Cancer Inst. 95: 437-448.

Wasylyk, C., Imler, J.L., Perez-Mutul, J., and Wasylyk, B. 1987. The c-Ha-ras oncogene and a tumor promoter activate the polyoma virus enhancer. Cell 48: 525-534.

Yamaguchi, Y. and Yoshikawa, K. 2001. Cutaneous wound healing: An update. J. Dermatol. 28: 521-534.

Zhang, L., Yu, D., Hu, M., Xiong, S., Lang, A., Ellis, L.M., and Pollock, R.E. 2000. Wild-type p53 suppresses angiogenesis in human leiomyosarcoma and synovial sarcoma by transcriptional suppression of vascular endothelial growth factor expression. Cancer Res. 60: 3655-3661. 


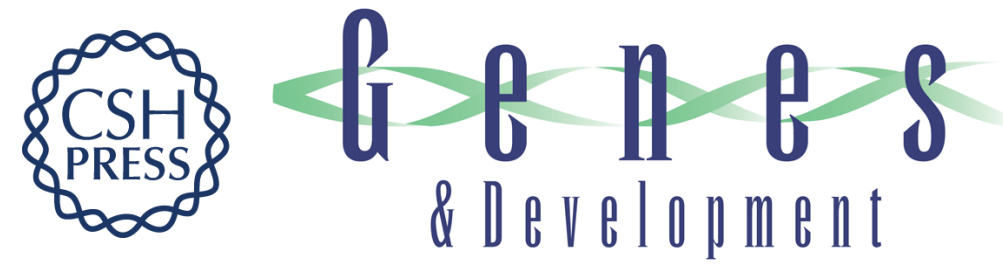

\section{The transcription factor Net regulates the angiogenic switch}

Hong Zheng, Christine Wasylyk, Abdelkader Ayadi, et al.

Genes Dev. 2003, 17:

Access the most recent version at doi:10.1101/gad.272503

References This article cites 75 articles, 35 of which can be accessed free at: http://genesdev.cshlp.org/content/17/18/2283.full.html\#ref-list-1

License

Email Alerting Receive free email alerts when new articles cite this article - sign up in the box at the top Service right corner of the article or click here.

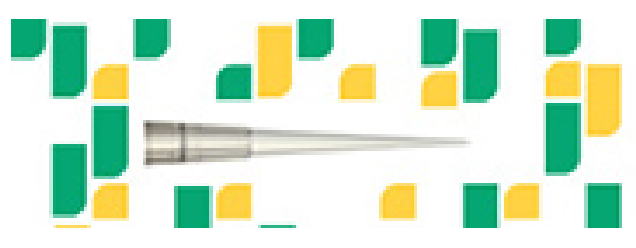

Focused on your science. 